\title{
WestVirginiaUniversity
}

THE RESEARCH REPOSITORY @ WVU

Graduate Theses, Dissertations, and Problem Reports

2017

\section{Time Perspective, Health Behaviors, and Wellbeing in Adults}

Jonathan J. K. Stoltman

Follow this and additional works at: https://researchrepository.wvu.edu/etd

\section{Recommended Citation}

Stoltman, Jonathan J. K., "Time Perspective, Health Behaviors, and Wellbeing in Adults" (2017). Graduate Theses, Dissertations, and Problem Reports. 6734.

https://researchrepository.wvu.edu/etd/6734

This Thesis is protected by copyright and/or related rights. It has been brought to you by the The Research Repository @ WVU with permission from the rights-holder(s). You are free to use this Thesis in any way that is permitted by the copyright and related rights legislation that applies to your use. For other uses you must obtain permission from the rights-holder(s) directly, unless additional rights are indicated by a Creative Commons license in the record and/ or on the work itself. This Thesis has been accepted for inclusion in WVU Graduate Theses, Dissertations, and Problem Reports collection by an authorized administrator of The Research Repository @ WVU. For more information, please contact researchrepository@mail.wvu.edu. 
Time Perspective, Health Behaviors, and Wellbeing in Adults

Jonathan J.K. Stoltman, MA

Thesis submitted

to the Eberly College of Arts and Sciences

at West Virginia University

in partial fulfillment of the requirements for the degree of

Master of Science in

Psychology

Julie Hicks Patrick, Ph.D., Chair

Steven Kinsey, Ph.D.

Aaron Metzger, Ph.D.

Department of Psychology

Morgantown, West Virginia

2017

Keywords: time orientation, CES-D, positive health behaviors, moderation Copyright 2017, Jonathan Joseph Kelly Stoltman 


\author{
Abstract \\ Time Perspective, Health Behaviors, and Wellbeing in Adults \\ Jonathan J.K. Stoltman, MA
}

An important component of health behavior engagement is time perspective. Previous research has demonstrated that individuals with a more expansive temporal perspective tend to engage in more positive and fewer negative health behaviors. Depression, the leading mood disorder, has diverse symptomatology and is associated with reduced positive future thinking. This study seeks to identify whether positive or negative health behaviors differentially effect the association between time perspective and depressive symptomatology. Participants $(n=106$; $M_{\text {age }}=35.2, \mathrm{SD}=12.7$, range $18-65 ; 71.7 \%$ female; $87.7 \%$ white) were drawn from a community sample recruited via digital message boards. The study took place over 8-days using experience sampling methodology to survey demographic variables, time perspective, and depressive symptomatology (i.e., CES-D total score). Daily health behaviors were assessed in the early evening for the past day. Results indicated CES-D total score was significantly, positively associated with positive future time perspective and negatively associated with positive health behavior engagement. An initial mediation was conducted to examine whether positive future time perspective influenced depression via health behaviors. Consistent with the correlation results, the a-path was not significant, thus there was not mediation. A moderation based on these initial correlations was completed to test the interaction between positive future time perspective and positive health behaviors. Results indicated a significant interaction such that, those with low positive future time perspective and low positive health behaviors endorsed the highest CES-D total score. Overall, as time perspective increased, depressive symptomatology decreased. The data suggest that positive health behavior engagement and time perspective are important to consider when developing or implementing treatments for depression. Future directions include fuller characterization of negative health behaviors, as well as investigation in clinically diagnosed populations. 
Disclosures / Acknowledgements

Research reported in this publication was supported by the National Institute of General Medical Sciences of the National Institutes of Health under Award Number U54GM104942. The content is solely the responsibility of the authors and does not necessarily represent the official views of the National Institutes of Health. 


\section{Table of Contents}

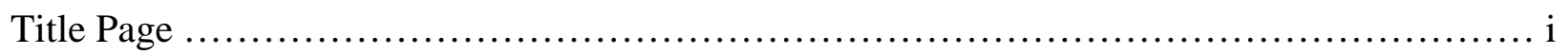

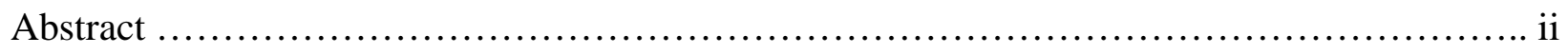

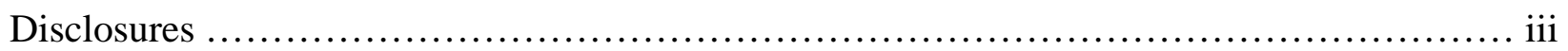

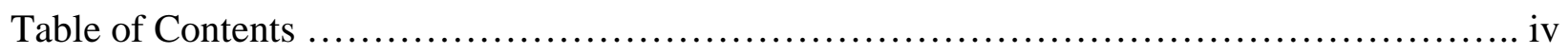

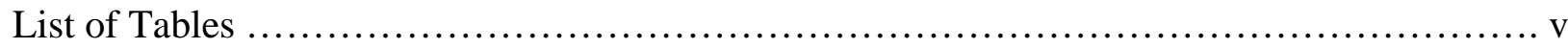

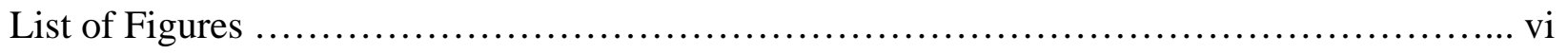

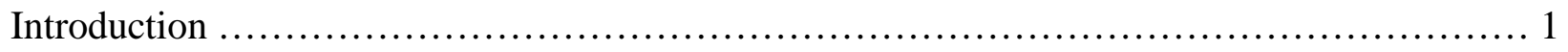

Summary and Current Study...................................................... 10

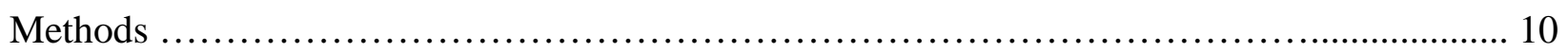

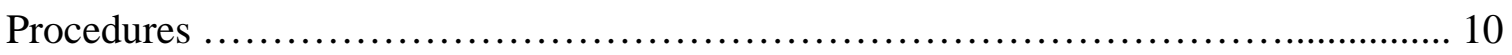

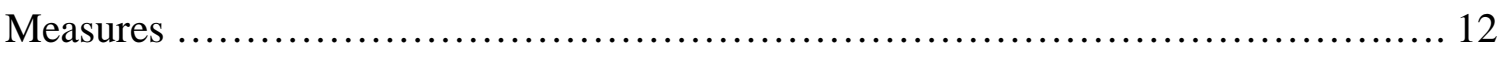

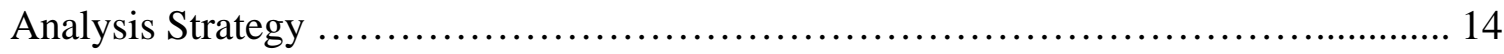

Results ......................................................................... 15

Preliminary Analyses ....................................................... 15

Bivariate Associations .......................................................... 15

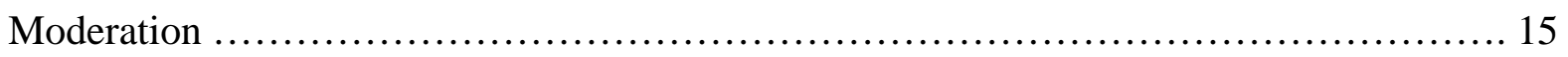

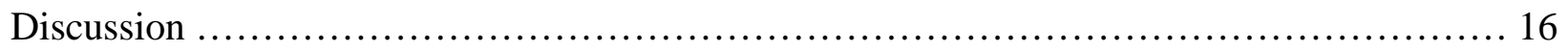

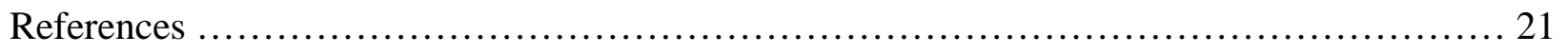

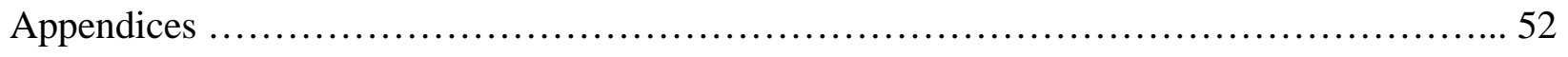


List of Tables

Table 1: Independent Samples T-Test Comparing Individuals with Complete Data (Included in The Moderation Analysis and Those Excluded from Moderation

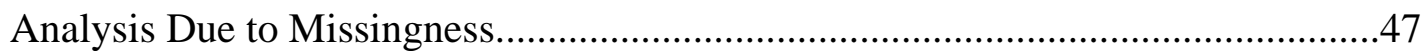

Table 2: Principal Component Analysis for Health Behaviors............................................48

Table 3: Pearson and Spearman Correlations Among Demographic, Time Perspective, Depression, and Health Behavior Variables.................................................49 


\section{List of Figures}

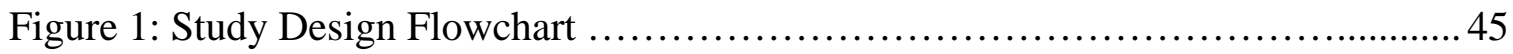

Figure 2: Participant Retention Flowchart ............................................................ 46

Figure 3: Mediation of the path between positive future time perspective's and depressive symptomatology by positive health behaviors ....................................50

Figure 4: Moderation of the path between positive future time perspective's and depressive symptomatology by positive health behaviors .....................................50

Figure 5: Moderated Regression Interpolation Table..................................................51 
Time Perspective, Health Behaviors, and Wellbeing in Adults

Preventable diseases due to lifestyle choices or modifiable health behaviors are the most common causes of morbidity and are associated with rising healthcare costs in the United States (Bauer, Briss, Goodman, \& Bowman, 2014; Lorenzoni, Belloni, \& Sassi, 2014). Among these diseases, depression is especially common. In fact, depression is the most common mood disorder in the United States (Kessler et al., 2009; Whiteford et al., 2013), affecting 6.7\% of adults (SAMSHA, 2016). Depression and depressive symptomatology are often entwined with a range of affective, behavioral, social, and physical/somatic complaints (Knight, Williams, McGee, \& Olaman, 1997; Williams et al., 2007). Although there are many correlates of depression, modifiable health behaviors are related to the vast majority of the health issues encountered in adulthood (Danaei et al., 2009). With a shift to a "graying” population (He, Goodkind, \& Kowal, 2016) better understanding how these behaviors might influence future health is a major concern to researchers and the public at large.

One characteristic of depression is the increased feelings of hopelessness, or negative feelings toward future events in addition to a reduced number of anticipated positive events (Beck, Weissman, Lester, \& Trexler, 1974; Lang \& Carstensen, 2002; MacLeod \& Salaminiou, 2001). This negative time orientation, a negative feeling toward future events in this instance, can also be investigated through the lens of time perspective. An individual's subjective relation to time, measured through various time perspective assessments, is a psychological construct that might explain why certain health behaviors persist, in spite of negative consequences (La Roche \& Frankel, 1986). For example, Socioemotional Selectivity Theory (Carstensen, 1991) suggests that as we age, our temporal horizon narrows such that we prioritize positive emotions over other goals or behaviors. Due to this seemingly intrinsic relation between time perspective and aging, 
much of the time perspective research has focused extensively on age effects. Health behaviors can also be affected by time perspective. For example, individuals with an expansive temporal perspective (i.e., higher future time perspective) tend to engage in more positive and fewer negative health behaviors (Stahl \& Patrick, 2012; Visser \& Hirsch, 2014). Taken together, both health behaviors and time perspective are malleable, and each relates to depression. However, little is known about their relation to depressive symptomatology. In addition, no study has comprehensively assessed whether the link between time perspective, health behaviors, and depressive symptomatology varies as a function of age or gender. Such information may help to develop age- and gender-sensitive interventions related to specific health behaviors.

\section{Time perspective}

Time perspective is defined as an individual's affective valence (i.e. positive or negative) toward time in relation to the past, present, or future (Paixão, da Silva, Ortuño, \& Cordeiro, 2013). Time perspective has been assessed using various scales, including: the Time Attitude Scale (Mello, Finan, \& Worrell, 2013), Zimbardo Time Perspective Inventory (Zimbardo \& Boyd, 1999), Balanced Time Perspective (Boniwell, Osin, Linley, \& Ivanchenko, 2010) and in various populations from French adolescents (Apostolidis, Fieulaine, \& Soulé, 2006) to Dutch adults (Kooij \& Van De Voorde, 2011), which provides evidence that across cultures, time perspective influences behavior (Boniwell et al., 2010; Worrell, Mello, \& Buhl, 2013). The different sub-constructs (i.e., positive future time perspective) have different implications for behavior (Zimbardo \& Boyd, 1999).

Future time perspective is a chief component of Socioemotional Selectivity Theory (Carstensen, 1991), which posits that goals change over one's lifetime based on an individual's perception of the future. As individuals age, they may be less motivated to change behaviors 
(observed through goal prioritization) based on perceived time left in life (Carstensen, 1995). For example, older adults, when compared to younger adults, are more selective with their friend and family interactions. Using data from the Oakland Growth Study, Carstensen (1992) found that although the frequency of interactions with friends decrease across adulthood, interactions with spouses and siblings increase in both quality and quantity.

Time perspective has been linked to health (Boniwell et al., 2010; Brown \& Segal, 1996; Gellert, Ziegelmann, Lippke, \& Schwarzer, 2011), with different aspects of time perspective related to various health outcomes. In cardiovascular health, for example, future perspective was associated with better disease management (Brown \& Segal, 1996) and greater perceived health responsibility (Hamilton, Kives, Micevski, \& Grace, 2003). Specifically, individuals with hypertension who were more future oriented were more likely to believe in the positive effects of their prescribed medication, less likely to believe in the effects of low efficacy home remedies, and believed that hypertension was more severe disease than individuals who were more present oriented (Brown \& Segal, 1996). A more present oriented time perspective is associated with various other negative health behaviors such as increased risky driving (Zimbardo, Keough, \& Boyd, 1997), increased substance use (Apostolidis et al., 2006; Keough, Zimbardo, \& Boyd, 1999; Petry, Bickel, \& Arnett, 1998), and decreased compliance with medical advice (Brown \& Segal, 1996; Lukwago et al., 2003). In contrast, a more expansive future time perspective has been associated with specific health-promoting behaviors, such as physical activity (Gellert et al., 2011; Stahl \& Patrick, 2012). Context and framing can influence time perspective, potentially making time perspective a manipulatable mechanism to increase positive health behaviors and to minimize negative health behaviors (Löckenhoff \& Carstensen, 2004; Stahl \& Patrick, 2012).

\section{Health behaviors}


Preventable diseases are commonly chronic in course and are typically noncommunicable (e.g., tobacco-related diseases; WHO, 2009). Interestingly, preventable diseases have increased in prevalence, while communicable diseases have reduced in prevalence (Lim et al., 2012). Typical preventable disease risk factors include lifestyle components such as: poor diet (e.g. insufficient fruits and vegetables: He, Nowson, Lucas, \& MacGregor, 2007), low exercise (Danaei et al., 2009), and substance use (tobacco: Oza, Thun, Henley, Lopez, \& Ezzati, 2011; alcohol: Rehm et al., 2009). These various favorable and detrimental health behaviors differentially impact health and morbidity (Lim et al., 2012; Lopez, Mathers, Ezzati, Jamison, \& Murray, 2006). According to the biopsychosocial model (Bauer et al., 2014; Borrell-Carrió, Suchman, \& Epstein, 2004), identifying psychological mechanisms contributing to preventable diseases could help reduce them. Engagement in positive health behaviors, as well as a reduction in negative health behaviors, is essential to individual mental health and overall functioning (Bauer et al., 2014; Jaffe \& Frieden, 2014; Woolf, 2008). Each is discussed in further detail below.

Positive health behaviors

Healthy diet maintenance is important to overall health and wellbeing (Jankovic et al., 2014; Lock, Pomerleau, Causer, Altmann, \& McKee, 2005) and can be assessed in various ways, such as vitamin use, fruit and vegetable intake, and daily water consumption.

While vitamin use has been shown to have little direct, positive impact on specific health condition risk reduction (e.g. cardiovascular health risks: Myung et al., 2013) and is associated with adverse side effects (Palmer et al., 2003; Timbo, Ross, McCarthy, \& Lin, 2006), health conscientious individuals generally endorse their use (Beitz, Gert, Hintzpeter, Fischer, \& Erbersdobler, 2004; Kirk, Cade, Barrett, \& Conner, 1999; Reinert, Rohrmann, Becker, \& 
Linseisen, 2007). Typically, individuals who take vitamins eat healthier, have lower body mass index, and often perceive themselves as healthier, thus taking vitamins is considered a health promoting behavior (for review, see: Masoodi, 2011; Ward, 2014). This practice is the foundation of the “inverse supplement hypothesis”, whereby vitamin users already engage in healthy eating, making the addition of vitamins redundant or non-essential (Kirk et al., 1999; Kirk, Woodhouse, \& Conner, 1998). In contrast, different use patterns have been noted in groups where vitamins are used to supplement unhealthy diets, finding that there are distinct classifications regarding healthy eating, with vitamin use present in all (van der Horst \& Siegrist, 2011). Although benefits are equivocal, vitamin use persists in various demographic groups (Conner, Kirk, Cade, \& Barrett, 2001; Gardiner, Buettner, Davis, Phillips, \& Kemper, 2009; Kirk et al., 1999; Reinert et al., 2007; Sebastian, Cleveland, Goldman, \& Moshfegh, 2007). Though vitamin use has mixed health benefits, it may serve as a proxy for other positive health conscientious behaviors.

Previous studies have assessed healthy diet through fruit and vegetable consumption (for review, see: Bazzano, 2006; Lock et al., 2005; Van Duyn \& Pivonka, 2000). Fruit and vegetable intake, at recommended levels, has health benefits such reduced stroke risk (He et al., 2007), reduced cardiovascular disease risk (Gan et al., 2015; Mirmiran, Noori, Zavareh, \& Azizi, 2009; Zhan et al., 2015), and reduced risk of metabolic disorder, such as Type II diabetes (Cooper et al., 2012; Muraki et al., 2013; Wu, Zhang, Jiang, \& Jiang, 2015). While fruit and vegetable consumption levels are low in the United States (Blanck, Gillespie, Kimmons, Seymour, \& Serdula, 2008; Demydas, 2011), because of the known health benefits, engagement in these behaviors would further suggest health conscientiousness. 
An additional healthy diet behavior is water intake (for review, see: Benelam \& Wyness, 2010; Horswill, 2011; Popkin, D'Anci, \& Rosenberg, 2010). Water can be consumed both passively through food and actively through beverages, depending on composition (Benelam \& Wyness, 2010; Sharp, 2007). Health organizations typically recommend that adults ingest about 2 liters or 64 ounces of water each day (Howard \& Bartram, 2003; IOM, 2005; Popkin et al., 2010; WHO, 2005). Water is essential to perform daily functional activities such as thermoregulation, excretion, and cardiac function (Horswill, 2011; Popkin et al., 2010). Dehydration, or insufficient water in an individuals’ system, can have deleterious effects on cognition (Lieberman, 2007) and overall health through interference with daily functional activities (Benelam \& Wyness, 2010). Typically, healthy beverage consumption is seen in conjunction with healthy food consumption (Duffey \& Popkin, 2006), thereby connecting these two health behaviors that are not seen as compensatory.

Lastly, sunscreen reduces the risk of sunburn (CDC, 2012; Sambandan \& Ratner, 2011; Wong \& Orton, 2011), skin aging (Fisher et al., 2002; Hughes, Williams, Baker, \& Green, 2013), and skin cancer (Green et al., 1999; Green, Williams, Logan, \& Strutton, 2011; Jolieke, Williams, Pandeya, Logan, \& Green, 2006). Skin cancer is the most prevalent cancer in the United States (Rogers et al., 2010). This cancer type is a preventable morbidity due to its known causes (e.g., prolonged ultraviolet radiation exposure) and responsiveness to preventative measures, including sunscreen (Linos et al., 2011; Simões, Sousa, \& Pais, 2015). Group differences in sunscreen use might explain increasing health and economic disease burden due to rising skin cancer incidence rates (Guy, Machlin, Ekwueme, \& Yabroff, 2015). For example, males and lower income groups are less likely to apply sunscreen, putting them at higher risk for 
ultraviolet radiation exposure conditions (Holman et al., 2015). Taken together, sunscreen use is an important health behavior toward decreasing sunburn and skin cancer risk.

Negative health behaviors

Since the Surgeon General’s report (1964), tobacco use has been thoroughly investigated for its possibly deleterious effects on health. Tobacco use, through its consequences, is considered the leading morbidity and chronic disease cause (Carter et al., 2015; CDC, 2008; Oza et al., 2011; Thun et al., 2013) reducing a smokers average life expectancy by more than 10 years (Jha et al., 2013). Interestingly, the risks associated with tobacco use are known by many smokers, though underestimated when considering disability and lung cancer (Oncken, McKee, Krishnan-Sarin, O'Malley, \& Mazure, 2005) potentially leading to continued use. In addition to an elevated cancer risk (Carter et al., 2015; Lee, Foley, \& Coombs, 2012; Siegel et al., 2015), regular tobacco users have elevated cardiovascular (Ambrose \& Barua, 2004; Armani, Landini Jr, \& Leone, 2009; Chen \& Boreham, 2002; Salahuddin, Prabhakaran, \& Roy, 2012) and pulmonary (Antoniou et al., 2013; Burney et al., 2014; Thun et al., 2013) consequences associated with their tobacco use. While public health campaigns (Levy, Ellis, Mays, \& AnTsun, 2013) and general awareness regarding negative tobacco use consequences have led to a smoking decline in recent years (Agaku, King, \& Dube, 2014; CDC, 2009, 2011b; Holford et al., 2014; Pierce, Messer, White, Cowling, \& Thomas, 2011; Secades-Villa et al., 2013), use persists, as do its sequela. These continued smoking rates may be due to the high transition rate (67.5\%) from initiation to dependence in nicotine users (Lopez-Quintero et al., 2011) and low use of validated smoking cessation techniques (CDC, 2011a). Considering its extensive, and in many cases chronic, negative consequences, tobacco use is an unequivocally negative health behavior. 
Similar to tobacco use, regular alcohol use has widespread negative health consequences (Corrao, Bagnardi, Zambon, \& La Vecchia, 2004; Grant et al., 2015; Rehm et al., 2009; Room, Babor, \& Rehm, 2005; WHO, 2014). Regular alcohol use is associated with decreased hepatic functioning, through liver cirrhosis (Liangpunsakul, Haber, \& McCaughan, 2016; Rehm, Samokhvalov, \& Shield, 2013; Rehm et al., 2010; White, Altmann, \& Nanchahal, 2002; Younossi \& Henry) and cancer (Bagnardi et al., 2015; Nelson et al., 2013; Pelucchi, Tramacere, Boffetta, Negri, \& Vecchia, 2011; Savage, 2014; Testino, Leone, Sumberaz, \& Borro, 2015). Due partially to its legal status and general acceptability, alcohol use is high in the United States (Schoenborn, Adams, \& Peregoy, 2013). Alcohol is the most commonly used psychoactive substance among adolescents; however, its use is in decline (Miech, Johnston, O’Malley, Bachman, \& Schulenberg, 2015). Confusion also persists regarding the "J" curve, summarized as advantageous regular alcohol use (i.e., $\leq 1$ glass for women, $\leq 2$ for men) that is potentially protective against certain cardiovascular risks (Di Castelnuovo et al., 2006; Di Castelnuovo, Costanzo, Donati, Iacoviello, \& de Gaetano, 2010; Huang et al., 2014; Matsumoto, Miedema, Ofman, Gaziano, \& Sesso, 2014). Whereas the research on positive benefits is equivocal, those related to the negative consequences are persistent and replicated. Therefore, regular alcohol use is considered to be a negative health behavior in the healthy living context.

While seatbelt use has become more of a public health priority in recent years, compliance issues persist (Dinh-Zarr et al., 2001; WHO, 2013). In the United States, compliance is considered a public health success with an increase from $14 \%$ as recently as the 1980 s to nearly $80 \%$ currently using seatbelts (Kahane, 2015). Though prevalence rates vary state-bystate and region by region due to variations in the law (Birru, Rudisill, Fabio, \& Zhu, 2016; Chen, 2015; Morgan, 2015; NHTSA, 2015; Pickrell, 2014), reduction in this negative health 
behavior has been successful through increases in high-level enforcement and fines (Nichols, Tippetts, Fell, Eichelberger, \& Haseltine, 2014). Non-compliance with seatbelt use presents elevated injury risk during accidents (Abu-Zidan, Abbas, Hefny, Eid, \& Grivna, 2011; NHSTA, 2000; NHTSA, 1984), resulting in economic productivity reduction due to injury recovery or chronic disease consequents (Blincoe, Miller, Zaloshnja, \& Lawrence, 2015). Aside from the injury risk, seat belt non-compliance might be a proxy for other risky behaviors (Ball, Kirkpatrick, \& Brenneman, 2005), making it a good indicator of negative health behaviors. In total, all the above negative health behaviors are preventable, but significantly contribute to overall morbidity and chronic disease risk (WHO, 2009).

\section{Aging, health, and depression in the United States}

Government reports project an increase in percentage of adults $65+$ from about $14.5 \%$ of the population to nearly $20 \%$ by 2050 as those in midlife shift to this older demographic (Ortman \& Velkoff, 2014). As the population ages, understanding the association between health behaviors and health conditions grows in importance.

Depression is a highly prevalent mental health condition, with multi-dimensional features effecting physical, physiological, and psychological functions (Kessler, Chiu, Demler, \& Walters, 2005; Kessler \& Üstün, 2008). Depression is often thought to be comprised of multiple dimensions, including high depressed affect, low positive affect, higher somatic complaints, and disrupted interpersonal relations (Knight et al., 1997; Williams et al., 2007), highlighting the different ways depression can manifest in an individual. The diverse symptoms of depression provide the opportunity to examine the specific effects of different correlates, to help improve intervention approaches and decrease overall disease burden, thereby improving healthy aging (DeRubeis, Siegle, \& Hollon, 2008). 


\section{Summary and the Current Study}

As the US and world population continue to age, it is important to identify means to support adults’ efforts to improve health through modifiable lifestyle behaviors. Because such health behaviors may be influenced by time perspective and a host of individual difference variables such as age (Andretta, Worrell, Mello, Dixson, \& Baik, 2013; Kooij \& Van De Voorde, 2011) and gender (Henson, Carey, Carey, \& Maisto, 2006; Mello \& Worrell, 2006), it may be important to include these variables in models examining depressive symptomatology. Additionally, we hope to learn more about the effect health behaviors have on the relationship between future time perspective and depressive symptomatology. As enumerated above, health behaviors and future time perspective have been found to have direct effects on depressive symptomatology, but the path through which they do so is unclear. Therefore, this study proposes to help better understand these associations but testing mediation and moderation effects.

\section{Research Questions}

How do specific health behaviors and future time perspective relate to overall depressive symptomatology? It is clear that future time perspective relates to depression (MacLeod \& Salaminiou, 2001). Moreover, future time perspective relates to specific health behaviors (Stahl \& Patrick, 2012; Visser \& Hirsch, 2014). What is less clear is whether health behaviors mediate or moderate the effect of future time perspective on depressive symptomatology.

\section{Methods}

\section{Procedures}


Data for these analyses are derived from a larger study $(N=174)$ examining daily affect and behaviors. Experience sampling methodology (ESM) was used to collect survey data between July 1, 2015, and December 31, 2015. Other than age ( $\geq 18$ years old) and having access to a device capable of receiving the daily experience sampling surveys, there were no exclusion criteria. Thus, broad recruitment efforts were used, including paid print ads, free online bulletin boards (e.g., Craigslist, Facebook), ads at local health and social events, and word of mouth. The West Virginia University Institutional Review Board approved this study.

The study protocol included a baseline survey, an 8-day experience sampling phase, and a follow-up survey. After completing a 9-page baseline survey (please see Figure 1), eligible adults were invited to begin the 8-day experience sampling phase of the study, beginning on the following Monday. Participants received brief ( $<3$ minutes) surveys each day at approximately 7:00 am, 1:00 pm, and 7:00 pm. A 2-hour response window was used at each ESM interval to prevent retrospective responding. The morning after the Day 8 of the ESM phase, participants received a 6-page follow-up survey, whose response window remained open for about 48 hours. Upon completion of the follow-up survey, participants were mailed a \$25 gift card.

Complete data for this study were provided by 106 adult participants. See Figure 2 for a flowchart depicting participant retention. Participants older than 65 were excluded from analysis after being identified as statistical outliers. Participants who had complete data for age, time perspective, and depressive symptomatology were included. Missing data are common in experience sampling studies, thus participants needed responses on $\geq 62.5 \%$ of the study days ( $50 \%$ of days +1$)$ to be included in the analysis. Therefore, participants missing health behavior responses on $>37.5 \%$ of days were excluded from final analysis. 
Independent samples t-tests were used to compare adults who were missing data on the variables of interest with adults who were included in our analyses. As shown in Table 1, few significant mean differences were detected, although those who were retained in the sample were younger in age $(M=35.21, \mathrm{SD}=12.67)$ relative to those who were excluded $(M=43.30, \mathrm{SD}=$ 18.65; $t(78.67)=2.87, p<.01)$. This finding may be due to age $(>65)$ as an exclusion criterion for the present analysis. Results for comparison between gender, positive future time perspective, CES-D total score, positive and negative health behaviors were not significant.

\section{Measures}

\section{Future time perspective}

Our Baseline survey used a recent adaptation of the Adolescent Time Inventory-Time Attitudes to assess future time perspective (ATI-TA, Mello \& Worrell, 2007). This instrument is cross-culturally reliable and valid in adolescents (Worrell \& Mello, 2009; Worrell et al., 2013) and adult age ranges (Mello et al., 2016). Items are endorsed on a 5- point Likert-type scale ranging from “Totally Disagree” to “Totally Agree”. Positive future time perspective items include questions such as: "thinking about my future excites me” and "I look forward to my future”. Although there are six temporal scales within the 30- question ATI-TA, only the future positive subscale is used in the current analyses. Overall, mean scores on positive future time perspective were consistent with previous research (Mello et al., 2016), with most participants reporting high positive future time perspective $(M=3.9$, $S D=.85 ; \alpha=.92-.93)$. Please see Appendix A for complete scale items.

$\underline{\text { Health behaviors }}$

Health behaviors that have been targeted in previous health campaigns were chosen for inclusion in this study. Each was surveyed each day at time 3, between 7p and 9p. Participants 
responded whether (“yes”/ ”no”/ ”not applicable”) they had: used tobacco products, drank eight or more glasses of water, eaten 1.5 to 2 servings of fruit, eaten 2.5 to 3 servings of vegetables, worn a seatbelt while in a car, used sunscreen, taken a vitamin, drank more than one serving of alcohol, or taken a nap. See Appendix A for question and response format. To best reflect endorsement of behaviors on the days reported, we accounted for a potentially uneven number of days the behaviors could be endorsed by calculating a proportion score for each individual health behavior. To do so, an individual's number of days endorsing a health behavior (“yes”) was divided by total response days for each health behavior (“yes”, “no”, and "not applicable”). We then summed the proportions, grouping them into either positive or negative health behavior categories. Exploratory and confirmatory principal component analyses (PCA) suggest two factors. For more information see Table 2.

Based on the 2-factor confirmatory PCA, health behaviors were characterized as negative (tobacco use, 2+ servings of alcohol, not wearing a seatbelt) or positive (water, fruit, vegetables, sunscreen use, vitamin). A final composite positive $(M=.35$, $S D=.25)$ or negative health behavior $(M=.13, S D=.18)$ score was generated using the proportional endorsement for each health behavior over the eight-day survey period. Due to the negative health behaviors’ poor distribution (44.3\% did not endorse engaging in any negative health behaviors over the 8 days) this variable was excluded from further analysis.

\section{Depressive symptoms}

Depressive symptomatology was assessed using the 20-item Center for Epidemiologic Studies - Depression Scale (CES-D: Radloff, 1977). Participants reported past-week frequency (less than 1 day, 1-2 days 3-4 days, 5-7 days) that they “felt sad” and “like they couldn’t get going”. The 20-items can be used as a total score or as subscales tapping depressed affect, 
positive affect, somatic complaints, and interpersonal relations (Knight et al., 1997; Shafer, 2006). Because of our small sample size, we focused on the overall score in which higher scores reflect more depressive symptomatology. In the attached supplements, we include exploratory post hoc tests with the subscales. In the current sample, the mean CES-D total score was 13.8 $(S D=11.3)$, with $29.3 \%$ meeting the cut-off for clinical referral $(\geq 16$ on the CES-D; Lewinsohn, Seeley, Roberts, \& Allen, 1997). For full-scale items, please refer to Appendix A.

\section{Analysis strategy}

Descriptive statistics, including means, standard deviations, skew and kurtosis, were used to characterize the sample and assess normality for: positive future time perspective [ATA-TI]; health behaviors; CES-D total score; and age. Apart from the positively skewed distribution for negative health behaviors, the data met the normality assumptions of the General Linear Model. Due to extreme positive skew in negative health behaviors, largely driven by $44.3 \%$ not endorsing any negative health behaviors over the 8 study days, this variable was excluded from analyses. Initial correlations (Table 3) were used to investigate the appropriateness of using a moderation and indirect model effects among depressive symptoms, future time perspective and health behaviors (Hayes, 2013).

To assess whether the association from positive future time perspective to depressive symptomatology was mediated or moderated by health behaviors, two separate analyses were conducted using the PROCESS macros for SPSS 24 (please see Figure 4; Hayes, 2009; Hayes, 2013; Preacher \& Hayes, 2004). Because we used multiple predictors and had a small sample, we used 5000 bootstrapping samples to provide stability to the beta weights (Fritz \& MacKinnon, 2007). This statistical technique is not without its limitations, as resampling might 
not generate an accurate population parameters due to the potential lack of representativeness of the initial sample estimates (Haukoos \& Lewis, 2005).

\section{Results}

\section{Demographic data}

The current sample included 106 adults, with a mean age of 35.2 years (SD = 12.7, range = 18-65 years). Our sample over-represents women (71.7\%). Gender was self-reported as either male or female. Although mostly non-Hispanic White (87.7\%) in racial identity, the sample includes 2.8\% African Americans and 7.6\% who identify as Hispanic.

\section{Bivariate associations}

Higher scores on the CES-D were significantly correlated with lower positive future time perspective $r(106)=-.539, p<.001$ and fewer positive health behaviors $r(106)=-.252 p<.01$. However, neither age $r(106)=.137, p=.160$, nor gender $r_{s}(106)=.018, p=.858$ were correlated with CES-D total score (Table 3). Based on these initial correlations, age and gender were not included in the primary models but, are included in a supplementary model based on the initial proposal (Appendix B). Positive future time perspective was not correlated with positive health behaviors $r(106)=.104, p=.29$.

\section{Mediation}

A mediation was used to test whether positive health behaviors effected the association between future time perspective and depressive symptomatology. According to the classic Baron and Kenny (1986) approach, four significant relations must be present in order to conclude that the mediator alters the association between the independent variable and the outcome. Specifically, a significant association between future time perspective and depressive

symptoms (path c) is required. Second, a significant association between future time perspective 
and positive health behaviors (path a) is required. In addition, positive health behaviors must be associated significantly with depressive symptoms (path b). Finally, when path a is considered, path c must become non-significant or zero (path c’). For the current data, path a from future time perspective to positive health behaviors was not significant $(b=.30 ; p=.29$ ), thus there was no mediation (Figure 3). This was anticipated, as there was no correlation between positive future time perspective and positive health behaviors $r(106)=.104, p=.29$. Main effects were observed between positive health behaviors and positive future time perspective predicting total depressive symptomatology.

\section{Moderation}

A moderation tested the interaction of positive health behaviors on the effect of future time perspective on depressive symptomatology. To avoid multicollinearity with the interaction term, the positive future time perspective and positive health behavior were centered. Overall, a significant total model was observed $F(3,102)=11.76, p<.001$, with $34.5 \%$ variance accounted for (see Figure 4). Both lower positive future time perspective $(b=-6.40)$ and fewer positive health behaviors ( $b=-10.36)$ were associated with more variance accounted for in depression. This finding was qualified by the significant interaction between positive future time perspective and positive health behaviors $F(1,102)=4.05, p<.05$, with $1.6 \%$ increase in variance accounted for. Interpolation table provided in Figure 5. Those with low positive future time perspective and low positive health behavior endorsement reported the highest depressive symptomatology. As positive future time perspective increased in the low positive health behavior group, depressive symptomatology reduced. Additionally, the group with low positive future time perspective and high positive health behavior endorsement reported the lowest depressive symptomatology and experienced a significant reduction with increased positive future time perspective. Overall, as 
time perspective increased, depressive symptomatology decreased in all three-positive health behavior endorsement groups.

\section{Discussion}

The present study investigated if future time perspective influenced depressive symptomatology in a small, though age diverse sample. Additionally, we examined what ways positive health behavior might alter the positive future time perspective to overall depressive symptomatology relation in a sample of 106 community-dwelling participants. Similar to previous research, positive future time perspective was associated with lower depressive symptomatology (MacLeod \& Salaminiou, 2001). The interaction between positive future time perspective and positive health behaviors manifested in two ways. Adults who reported higher positive future time perspective and higher positive health behavior engagement was associated with lower depressive symptomatology. Additionally, those with fewer positive health behaviors and lower positive future time perspective had the highest depressive symptomatology. This cross-sectional data suggests that positive health behavior endorsement functions as a moderator for the relation between positive future time perspective and depressive symptomatology. The mediation model was not significant, as positive future time perspective was not associated with positive health behavior engagement though direct effects for positive future time perspective and positive health behavior engagement were observed.

Due to the high disease burden of depression (Kessler et al., 2009; Whiteford et al., 2013), understanding the factors that underlie its’ diverse symptomatology continues to be of clinical importance. Depression is multidimensional in nature, and to address this, there are a number of current treatments, ranging from pharmacotherapy to cognitive behavioral approaches (DeRubeis et al., 2008). Interventions targeting future time perspective or health behaviors could 
serve as an adjunct to current depression treatment to improve patient outcomes. While decreased time perspective and decreased positive health behavior engagement are associated with increased depressive symptomatology, an interaction between these two potential causative factors provides insight into other mechanisms of treatment. Possible implications, theoretical explanations, and limitations are discussed below.

As we age, priorities tend to shift toward behaviors that are pleasurable, a phenomenon characterized as the Socioemotional Selectivity Theory (Carstensen, 1991). This shift towards immediately positive behaviors might be due to the reduced temporal perspective inherent in aging, such that, as we age our perception of "time left" can be a powerful motivator. Adults with higher future time perspective engage in more positive health behaviors (Stahl \& Patrick, 2012; Visser \& Hirsch, 2014). Disparate time perspectives could account for the difference in the low positive health behavior endorsement sub-group. As time perspective increased, there was lower overall depressive symptomatology, thus suggesting that boosting future thinking might be a more effective intervention for the low positive health behavior group. Ultimately, those with the lowest overall depressive symptomatology had the highest future thinking, but were not significantly different across positive health behavior endorsement.

To improve outcomes in this group, time perspective could be modified. Therefore, time perspective may be used as a potential target for selecting and developing strategies to increase positive health behaviors. MacLeod and Salaminiou (2001) show reduced positive future time perspective is associated with depression, thereby highlighting a possible intervention target. Unhealthy eaters have less consideration for future health, thus leveraging interventions that target healthy eating could provide the benefits of improved positive future time perspective through increased healthy eating habits (Dassen, Houben, \& Jansen, 2015; Gick, 2014). 
Furthermore, engaging in healthy eating could reduce health risks that might lead to cancer (Kaplan, Reed, \& Jarmolowicz, 2016). Experimental conditions have modified time perspective through encouraging long-range thinking, or episodic future thinking (EFT; for review see: Atance \& O'Neill, 2001; Szpunar, 2010). Previously this has been shown to increase healthy eating (Daniel, Stanton, \& Epstein, 2013a; Daniel, Stanton, \& Epstein, 2013b) and reduce alcohol impairment effects (Paraskevaides et al., 2009). To be effective as a treatment or experimental condition, the scenarios need to be plausible because it is not an inability to think it can happen, rather the inability to believe it can happen to them (MacLeod \& Conway, 2007).

Separately, positive health behavior endorsement could help buffer the effects of low future time perspective. In our sample, those who endorsed high positive health behavior engagement were lowest in overall depressive symptomatology. This difference was most pronounced in the group with low future time perspective. The Behavioral Activation Treatment approach might indirectly target this effect and could work best in a subset of individuals with low future time perspective. Behavioral activation is a recent treatment for patients with depression that relies on behavior modification to improve outcomes (Cuijpers, Van Straten, \& Warmerdam, 2007). Outcomes for behavioral activation can outperform cognitive behavioral therapy and perform on-par with pharmacotherapy (DeRubeis et al., 2008), but more work is needed to understand cognitive behavior therapies' mechanism of action. Additionally, relatively scant research has explored what might be more beneficial, reduction in negative behaviors or engagement in positive behaviors.

These findings and interpretations are not without limitations. For example, participants might be less willing to enter negative health behaviors than positive health behaviors. While negative health behavior reduction might also be beneficial in reducing depressive 
symptomatology, $44.3 \%$ of this sample did not report engaging in any negative health behaviors in the 8 days surveyed. The complete lack of self-reported negative health behaviors prevented any analysis of this potential moderator. Furthermore, the absence of positive or negative health behaviors could be the presence of the opposite (e.g., buckling your seatbelt is a positive health behavior), but this scenario was not considered in the current model. While eight days of ecological momentary data collection can serve as a snapshot of health behaviors, the chosen interval may have been too short to truly encapsulate the behaviors assessed. Additionally, finergrain measurement of health behaviors, especially negative health behaviors, might lead to better understanding of their interaction with positive future time perspective. For example, CDC fruit and vegetable consumption guidelines suggest differences based on gender, but these recommendations were averaged in the present study to make response selection more straightforward for participants, as previously reported (Moore \& Thompson, 2015). Vitamin use can also be surveyed more intensively, with recent trends observing a decrease in multivitamin use and a concomitant increase in specific supplements or single vitamin formulations (Kantor, Rehm, Du, White, \& Giovannucci, 2016). This recent trend suggests that assessing the use of single vitamins or supplements might serve as a better proxy of "health” behaviors. Study timing might also contribute to health behavior engagement. For example, the recruitment period began in December. While sunscreen is always advised, it is plausible that these participants might not have applied sunscreen regularly, although they may have expressed other positive health behaviors. Additionally, sunscreen self-report data have been compared to urinary benzophenone-3, a sunscreen use bi-product, and results suggest self-reported sunscreen is an accurate measure (Zamoiski, Cahoon, Freedman, \& Linet, 2015). Considering these limitations, a broader range of health behaviors could characterize the health in a more granular fashion and 
include other non-surveyed health behaviors such as exercise (intensity and frequency) or sleep behaviors.

The threshold for a clinical depression diagnosis (> 15 on the CES-D; Lewinsohn et al., 1997) was met for $29.3 \%$ of the sample, but there were no diagnoses provided by a trained clinician. Thus, our discussion is limited to self-reported symptoms. It is also possible that socioeconomic status serves as a covariate in this analysis, but this was unmeasured in the current database. Future research could include more information on socioeconomic status and scarcity, a shared concept which might affect future planning and behavior engagement (Epstein et al., 2014). Scarcity can shift temporal horizons to the urgent, immediate time frame, further emphasizing the importance of including this variable in future projects (Epstein et al., 2014; Jabs \& Devine, 2006). Sample considerations might include improving the gender and race/ethnicity distribution to better represent the general population. A lack of diversity in the sample limits the ability to test sub-group differences in a way that might benefit precision medical interventions. Lastly, this data is cross-sectional, limiting interpretation of causation. That is, time perspective and depressive symptomatology were measured contemporaneously, thus it is difficult to discern directionality. This research does encourage future, longitudinal investigations utilizing multiple time points to better understand the relation between time perspective and depression.

Given that health outcomes are strongly influenced by lifestyle factors (Khera et al., 2016), more research can be done to understand the role they play in depression, the leading mental health disease burden (Kessler et al., 2009; Whiteford et al., 2013). Our findings suggest that the effect of positive future time perspective on overall depressive symptomatology is moderated by past 8-day positive health behavior endorsement. Based on these findings, 
experimental conditions or treatment targeting the highly malleable positive health behaviors, as well as increasing the future temporal perspective could improve depression treatment outcomes. 


\section{References}

Abu-Zidan, F. M., Abbas, A. K., Hefny, A. F., Eid, H. O., \& Grivna, M. (2011). Effects of seat belt usage on injury pattern and outcome of vehicle occupants after road traffic collisions: Prospective study. World Journal of Surgery, 36(2), 255-259. doi:10.1007/s00268-011$1386-\mathrm{y}$

Agaku, I. T., King, B. A., \& Dube, S. R. (2014). Current cigarette smoking among adultsUnited States, 2005-2012.

Ambrose, J. A., \& Barua, R. S. (2004). The pathophysiology of cigarette smoking and cardiovascular disease: An update. Journal of the American College of Cardiology, 43(10), 1731-1737. doi:http://dx.doi.org/10.1016/j.jacc.2003.12.047

Andretta, J. R., Worrell, F. C., Mello, Z. R., Dixson, D. D., \& Baik, S. H. (2013). Demographic group differences in adolescents' time attitudes. J Adolesc, 36(2), 289-301. doi:10.1016/j.adolescence.2012.11.005

Antoniou, K. M., Walsh, S. L., Hansell, D. M., Rubens, M. R., Marten, K., Tennant, R., .. . Wells, A. U. (2013). Smoking-related emphysema is associated with idiopathic pulmonary fibrosis and rheumatoid lung. Respirology, 18(8), 1191-1196. doi:10.1111/resp.12154

Apostolidis, T., Fieulaine, N., \& Soulé, F. (2006). Future time perspective as predictor of cannabis use: Exploring the role of substance perception among French adolescents. Addict Behav, 31(12), 2339-2343. doi:http://dx.doi.org/10.1016/j.addbeh.2006.03.008 
Armani, C., Landini Jr, L., \& Leone, A. (2009). Molecular and biochemical changes of the cardiovascular system due to smoking exposure. Current Pharmaceutical Design, 15(10), 1038-1053.

Atance, C. M., \& O'Neill, D. K. (2001). Episodic future thinking. Trends Cogn Sci, 5(12), 533539. doi:http://dx.doi.org/10.1016/S1364-6613(00)01804-0

Bagnardi, V., Rota, M., Botteri, E., Tramacere, I., Islami, F., Fedirko, V., . . Pasquali, E. (2015). Alcohol consumption and site-specific cancer risk: A comprehensive dose-response meta-analysis. British Journal of Cancer, 112(3), 580-593.

Ball, C. G., Kirkpatrick, A. W., \& Brenneman, F. D. (2005). Noncompliance with seat-belt use in patients involved in motor vehicle collisions. Canadian Journal of Surgery, 48(5), 367-372.

Baron, R. M., \& Kenny, D. A. (1986). The moderator-mediator variable distinction in social psychological research: Conceptual, strategic, and statistical considerations. Journal of Personality and Social Psychology, 51(6), 1173.

Bauer, U. E., Briss, P. A., Goodman, R. A., \& Bowman, B. A. (2014). Prevention of chronic disease in the 21st century: Elimination of the leading preventable causes of premature death and disability in the USA. The Lancet, 384(9937), 45-52. doi:10.1016/S01406736(14)60648-6

Bazzano, L. A. (2006). The high cost of not consuming fruits and vegetables. Journal of the American Dietetic Association, 106(9), 1364-1368. doi:http://dx.doi.org/10.1016/j.jada.2006.06.021

Beck, A. T., Weissman, A., Lester, D., \& Trexler, L. (1974). The measurement of pessimism: the hopelessness scale. Journal of consulting and clinical psychology, 42(6), 861. 
Beitz, R., Gert, B. M. M., Hintzpeter, B., Fischer, B., \& Erbersdobler, H. F. (2004). Do users of dietary supplements differ from nonusers in their food consumption? European Journal of Epidemiology, 19(4), 335-341.

Benelam, B., \& Wyness, L. (2010). Hydration and health: A review. Nutrition Bulletin, 35(1), 325.

Birru, H., Rudisill, T. M., Fabio, A., \& Zhu, M. (2016). A comparison of self-reported seat belt usage among the Appalachian and non-Appalachian United States. Annals of Epidemiology, 26(3), 227-230. doi:http://dx.doi.org/10.1016/j.annepidem.2016.02.001

Blanck, H. M., Gillespie, C., Kimmons, J. E., Seymour, J. D., \& Serdula, M. K. (2008). Trends in fruit and vegetable consumption among US men and women, 1994-2005. Preventing Chronic Disease, 5(2).

Blincoe, L., Miller, T. R., Zaloshnja, E., \& Lawrence, B. A. (2015). The economic and societal impact of motor vehicle crashes, 2010 (Revised). Retrieved from

Boniwell, I., Osin, E., Linley, P. A., \& Ivanchenko, G. V. (2010). A question of balance: Time perspective and well-being in British and Russian samples. The Journal of Positive Psychology, 5(1), 24-40.

Borrell-Carrió, F., Suchman, A. L., \& Epstein, R. M. (2004). The Biopsychosocial Model 25 Years Later: Principles, Practice, and Scientific Inquiry. Annals of Family Medicine, 2(6), 576-582. doi:10.1370/afm.245

Brown, C. M., \& Segal, R. (1996). Ethnic differences in temporal orientation and its implications for hypertension management. Journal of Health and Social Behavior, 37(4), 350-361.

Burney, P., Jithoo, A., Kato, B., Janson, C., Mannino, D., Nizankowska-Mogilnicka, E., .. . Burden Obstructive Lung Dis, B. (2014). Chronic obstructive pulmonary disease 
mortality and prevalence: The associations with smoking and poverty - a BOLD analysis. THORAX, 69(5). doi:10.1136/thoraxjnl-2013-204460

Carstensen, L. L. (1991). Selectivity theory: Social activity in life-span context. Annual Review of Gerontology and Geriatrics, 11, 195-217.

Carstensen, L. L. (1992). Social and emotional patterns in adulthood: Support for socioemotional selectivity theory. Psychol Aging, 7(3), 331-338.

Carstensen, L. L. (1995). Evidence for a life-span theory of socioemotional selectivity. Current Directions in Psychological Science, 4(5), 151-156.

Carter , B. D., Abnet , C. C., Feskanich , D., Freedman , N. D., Hartge , P., Lewis , C. E., .. . Jacobs , E. J. (2015). Smoking and mortality — Beyond established causes. New England Journal of Medicine, 372(7), 631-640. doi:doi:10.1056/NEJMsa1407211

CDC. (2008). Smoking-attributable mortality, years of potential life lost, and productivity losses-United States, 2000-2004. MMWR. Morbidity and mortality weekly report, 57(45), 1226.

CDC. (2009). Cigarette smoking among adults and trends in smoking cessation-United States, 2008. MMWR. Morbidity and mortality weekly report, 58(44), 1227.

CDC. (2011a). Quitting smoking among adults--United States, 2001-2010. MMWR Morb Mortal Wkly Rep, 60(44), 1513-1519.

CDC. (2011b). Vital signs: current cigarette smoking among adults aged $>/=18$ years--United States, 2005-2010. MMWR Morb Mortal Wkly Rep, 60(35), 1207-1212.

CDC. (2012). Sunburn and sun protective behaviors among adults aged 18-29 years, United States, 2000-2010. Morbidity and Mortality Weekly Report, 61(18), 317-322.

Chen, Y. Y. (2015). Seat belt use in 2014-Use rates in the states and territories. 
Chen, Z., \& Boreham, J. (2002). Smoking and cardiovascular disease. Seminars in Vascular Medicine, 02(03), 243-252. doi:10.1055/s-2002-35392

Conner, M., Kirk, S. F. L., Cade, J. E., \& Barrett, J. H. (2001). Why do women use dietary supplements? The use of the theory of planned behaviour to explore beliefs about their use. Social Science \& Medicine, 52(4), 621-633. doi:http://dx.doi.org/10.1016/S0277-

\section{$\underline{9536(00) 00165-9}$}

Cooper, A. J., Forouhi, N. G., Ye, Z., Buijsse, B., Arriola, L., Balkau, B., . . B Büchner, F. L. (2012). Fruit and vegetable intake and type 2 diabetes: EPIC-InterAct prospective study and meta-analysis. European Journal of Clinical Nutrition, 66(10), 1082-1092.

Corrao, G., Bagnardi, V., Zambon, A., \& La Vecchia, C. (2004). A meta-analysis of alcohol consumption and the risk of 15 diseases. Preventive Medicine, 38(5), 613-619. doi:http://dx.doi.org/10.1016/j.ypmed.2003.11.027

Cuijpers, P., Van Straten, A., \& Warmerdam, L. (2007). Behavioral activation treatments of depression: A meta-analysis. Clinical psychology review, 27(3), 318-326.

Danaei, G., Ding, E. L., Mozaffarian, D., Taylor, B., Rehm, J., Murray, C. J. L., \& Ezzati, M. (2009). The preventable causes of death in the United States: Comparative risk assessment of dietary, lifestyle, and metabolic risk factors. PLoS Med, 6(4), e1000058. doi:10.1371/journal.pmed.1000058

Daniel, T. O., Stanton, C. M., \& Epstein, L. H. (2013a). The future is now: Comparing the effect of episodic future thinking on impulsivity in lean and obese individuals. Appetite, 71, 120-125. doi:http://dx.doi.org/10.1016/j.appet.2013.07.010 
Daniel, T. O., Stanton, C. M., \& Epstein, L. H. (2013b). The future is now: reducing impulsivity and energy intake using episodic future thinking. Psychol Sci, 24(11), 2339-2342. doi:10.1177/0956797613488780

Dassen, F. C. M., Houben, K., \& Jansen, A. (2015). Time orientation and eating behavior: Unhealthy eaters consider immediate consequences, while healthy eaters focus on future health. Appetite, 91, 13-19. doi:http://dx.doi.org/10.1016/j.appet.2015.03.020

Demydas, T. (2011). Consumer segmentation based on the level and structure of fruit and vegetable intake: An empirical evidence for US adults from the National Health and Nutrition Examination Survey (NHANES) 2005-2006. Public health nutrition, 14(06), 1088-1095. doi:doi:10.1017/S1368980010003745

DeRubeis, R. J., Siegle, G. J., \& Hollon, S. D. (2008). Cognitive therapy versus medication for depression: treatment outcomes and neural mechanisms. Nat Rev Neurosci, 9(10), 788796.

Di Castelnuovo, A., Costanzo, S., Bagnardi, V., Donati, M., Iacoviello, L., \& de Gaetano, G. (2006). Alcohol dosing and total mortality in men and women: An updated meta-analysis of 34 prospective studies. Archives of Internal Medicine, 166(22), 2437-2445. doi:10.1001/archinte.166.22.2437

Di Castelnuovo, A., Costanzo, S., Donati, M. B., Iacoviello, L., \& de Gaetano, G. (2010). Prevention of cardiovascular risk by moderate alcohol consumption: Epidemiologic evidence and plausible mechanisms. Internal and Emergency Medicine, 5(4), 291-297. doi:10.1007/s11739-010-0346-0

Dinh-Zarr, T. B., Sleet, D. A., Shults, R. A., Zaza, S., Elder, R. W., Nichols, J. L., ... Sosin, D. M. (2001). Reviews of evidence regarding interventions to increase the use of safety 
belts. American Journal of Preventive Medicine, 21(4, Supplement 1), 48-65. doi:http://dx.doi.org/10.1016/S0749-3797(01)00378-6

Duffey, K. J., \& Popkin, B. M. (2006). Adults with healthier dietary patterns have healthier beverage patterns. The Journal of Nutrition, 136(11), 2901-2907.

Epstein, L. H., Jankowiak, N., Lin, H., Paluch, R., Koffarnus, M. N., \& Bickel, W. K. (2014). No food for thought: Moderating effects of delay discounting and future time perspective on the relation between income and food insecurity. The American Journal of Clinical Nutrition, 100(3), 884-890. doi:10.3945/ajcn.113.079772

Field, A. (2013). Discovering statistics using IBM SPSS statistics: Sage.

Fisher, G. J., Kang, S., Varani, J., Bata-Csorgo, Z., Wan, Y., Datta, S., \& Voorhees, J. J. (2002). Mechanisms of photoaging and chronological skin aging. Archives of Dermatology, 138(11), 1462-1470. doi:10.1001/archderm.138.11.1462

Fritz, M. S., \& MacKinnon, D. P. (2007). Required sample size to detect the mediated effect. Psychological Science, 18(3), 233-239. doi:10.1111/j.1467-9280.2007.01882.x

Gan, Y., Tong, X., Li, L., Cao, S., Yin, X., Gao, C., . . Lu, Z. (2015). Consumption of fruit and vegetable and risk of coronary heart disease: A meta-analysis of prospective cohort studies. International Journal of Cardiology, 183, 129-137. doi:http://dx.doi.org/10.1016/j.ijcard.2015.01.077

Gardiner, P., Buettner, C., Davis, R. B., Phillips, R. S., \& Kemper, K. J. (2009). Factors and common conditions associated with adolescent dietary supplement use: An analysis of the National Health and Nutrition Examination Survey (NHANES). BMC Complementary and Alternative Medicine, 8(1), 9-9. doi:10.1186/1472-6882-8-9 
Gellert, P., Ziegelmann, J. P., Lippke, S., \& Schwarzer, R. (2011). Future time perspective and health behaviors: Temporal framing of self-regulatory processes in physical exercise and dietary behaviors. Annals of Behavioral Medicine, 43(2), 208-218. doi:10.1007/s12160011-9312-y

Gick, M. (2014). An exploration of interactions between Conscientiousness and Consideration of Future Consequences on healthy eating. Personality and Individual Differences, 66, 181187. doi:http://dx.doi.org/10.1016/j.paid.2014.03.020

Grant, B. F., Goldstein, R. B., Saha, T. D., Chou, S. P., Jung, J., Zhang, H., . . Huang, B. (2015). Epidemiology of DSM-5 alcohol use disorder: Results from the National Epidemiologic Survey on Alcohol and Related Conditions III. JAMA Psychiatry, 72(8), 757-766.

Green, A. C., Williams, G., Neale, R., Hart, V., Leslie, D., Parsons, P., . . Russell, A. (1999). Daily sunscreen application and betacarotene supplementation in prevention of basal-cell and squamous-cell carcinomas of the skin: A randomised controlled trial. The Lancet, 354(9180), 723-729.

Green, A. C., Williams, G. M., Logan, V., \& Strutton, G. M. (2011). Reduced melanoma after regular sunscreen use: Randomized trial follow-up. Journal of Clinical Oncology, 29(3), 257-263. doi:10.1200/JCO.2010.28.7078

Guy, G. P., Machlin, S. R., Ekwueme, D. U., \& Yabroff, K. R. (2015). Prevalence and costs of skin cancer treatment in the U.S., 2002-2006 and 2007-2011. American Journal of Preventive Medicine, 48(2), 183-187. doi:http://dx.doi.org/10.1016/j.amepre.2014.08.036 
Hamilton, J. M., Kives, K. D., Micevski, V., \& Grace, S. L. (2003). Time perspective and healthpromoting behavior in a cardiac rehabilitation population. Behavioral Medicine, 28(4), 132-139 138p.

Haukoos, J. S., \& Lewis, R. J. (2005). Advanced statistics: Bootstrapping confidence intervals for statistics with “difficult” distributions. Academic Emergency Medicine, 12(4), 360365.

Hayes, A. F. (2009). Beyond Baron and Kenny: Statistical mediation analysis in the new millennium. Communication Monographs, 76(4), 408-420. doi:10.1080/03637750903310360

Hayes, A. F. (2013). Introduction to mediation, moderation, and conditional process analysis: A regression-based approach: Guilford Press.

He, F. J., Nowson, C. A., Lucas, M., \& MacGregor, G. A. (2007). Increased consumption of fruit and vegetables is related to a reduced risk of coronary heart disease: Meta-analysis of cohort studies. Journal of Human Hypertension, 21(9), 717-728.

doi:10.1038/sj.jhh.1002212

He, W., Goodkind, D., \& Kowal, P. (2016). An Aging World: 2015. Washington, D.C.: U.S. Government Publishing Office.

Henson, J. M., Carey, M. P., Carey, K. B., \& Maisto, S. A. (2006). Associations among health behaviors and time perspective in young adults: Model testing with boot-strapping replication. Journal of Behavioral Medicine, 29(2), 127-137. doi:10.1007/s10865-0059027-2 
Holford, T. R., Meza, R., Warner, K. E., Meernik, C., Jeon, J., Moolgavkar, S. H., \& Levy, D. T. (2014). Tobacco control and the reduction in smoking-related premature deaths in the United States, 1964-2012. JAMA, 311(2), 164-171. doi:10.1001/jama.2013.285112

Holman, D. M., Berkowitz, Z., Guy Jr, G. P., Hawkins, N. A., Saraiya, M., \& Watson, M. (2015). Patterns of sunscreen use on the face and other exposed skin among US adults. Journal of the American Academy of Dermatology, 73(1), 83-92.e81. doi:http://dx.doi.org/10.1016/j.jaad.2015.02.1112

Horswill, C. A. (2011). Hydration and health. American Journal of Lifestyle Medicine, 5(4), 304315. doi:10.1177/1559827610392707

Howard, G., \& Bartram, J. (2003). Domestic water quantity, service level, and health: World Health Organization Geneva.

Huang, C., Zhan, J., Liu, Y. J., Li, D. J., Wang, S. Q., \& He, Q. Q. (2014). Association between alcohol consumption and risk of cardiovascular disease and all-cause mortality in patients with hypertension: A meta-analysis of prospective cohort studies. Mayo Clinic Proceedings, 89(9), 1201-1210. doi:10.1016/j.mayocp.2014.05.014

Hughes, M. C. B., Williams, G. M., Baker, P., \& Green, A. C. (2013). Sunscreen and prevention of skin aging a randomized trial. Annals of Internal Medicine, 158(11), 781-781. doi:10.7326/0003-4819-158-11-201306040-00002

IOM. (2005). Dietary reference intakes for water, potassium, sodium, chloride, and sulfate: National Academy Press.

Jabs, J., \& Devine, C. M. (2006). Time scarcity and food choices: An overview. Appetite, 47(2), 196-204. 
Jaffe, H. W., \& Frieden, T. R. (2014). Improving health in the USA: Progress and challenges. The Lancet, 384(9937), 3-5. doi:10.1016/S0140-6736(14)61032-1

Jankovic, N., Geelen, A., Streppel, M. T., de Groot, L. C., Orfanos, P., van den Hooven, E. H., . . . Feskens, E. J. (2014). Adherence to a healthy diet according to the World Health Organization guidelines and all-cause mortality in elderly adults from Europe and the United States. Am J Epidemiol, 180(10), 978-988. doi:10.1093/aje/kwu229

Jha , P., Ramasundarahettige , C., Landsman , V., Rostron , B., Thun , M., Anderson , R. N., ... Peto , R. (2013). 21st-century hazards of smoking and benefits of cessation in the United States. New England Journal of Medicine, 368(4), 341-350.

doi:doi:10.1056/NEJMsa1211128

Jolieke, C. P., Williams, G. M., Pandeya, N., Logan, V., \& Green, A. C. (2006). Prolonged prevention of squamous cell carcinoma of the skin by regular sunscreen use. Cancer Epidemiology Biomarkers \& Prevention, 15(12), 2546-2548. doi:10.1158/10559965.EPI-06-0352

Kahane, C. J. (2015). Lives saved by vehicle safety technologies and associated federal motor vehicle safety standards, 1960 to 2012 passenger cars and ltvs with reviews of 26 FMVSS and the effectiveness of their associated safety technologies in reducing fatalities, injuries, and crashes. Paper presented at the 24th Technical Conference on the Enhanced Safety of Vehicles, Gothenburg, Sweden.

Kantor, E. D., Rehm, C. D., Du, M., White, E., \& Giovannucci, E. L. (2016). Trends in dietary supplement use among us adults from 1999-2012. JAMA, 316(14), 1464-1474. doi:10.1001/jama.2016.14403 
Kaplan, B. A., Reed, D. D., \& Jarmolowicz, D. P. (2016). Effects of episodic future thinking on discounting: Personalized age-progressed pictures improve risky long-term health decisions. Journal of Applied Behavior Analysis, 49(1), 148-169. doi:10.1002/jaba.277

Keough, K. A., Zimbardo, P. G., \& Boyd, J. N. (1999). Who's smoking, drinking, and using drugs? Time perspective as a predictor of substance use. Basic \& Applied Social Psychology, 21(2), 149-164.

Kessler, R. C., Aguilar-Gaxiola, S., Alonso, J., Chatterji, S., Lee, S., Ormel, J., . . Wang, P. S. (2009). The global burden of mental disorders: An update from the WHO World Mental Health (WMH) Surveys. Epidemiologia e psichiatria sociale, 18(1), 23-33.

Kessler, R. C., Chiu, W., Demler, O., \& Walters, E. E. (2005). Prevalence, severity, and comorbidity of 12-month DSM-IV disorders in the national comorbidity survey replication. Archives of General Psychiatry, 62(6), 617-627.

doi:10.1001/archpsyc.62.6.617

Kessler, R. C., \& Üstün, T. B. (2008). The WHO World Mental Health Surveys: Global perspectives on the epidemiology of mental disorders: Cambridge University Press New York.

Khera, A. V., Emdin, C. A., Drake, I., Natarajan, P., Bick, A. G., Cook, N. R., . . Kathiresan, S. (2016). Genetic Risk, Adherence to a Healthy Lifestyle, and Coronary Disease. New England Journal of Medicine, O(0), null. doi:doi:10.1056/NEJMoa1605086

Kirk, S. F., Cade, J. E., Barrett, J. H., \& Conner, M. (1999). Diet and lifestyle characteristics associated with dietary supplement use in women. Public health nutrition, 2(01), 69-73. 
Kirk, S. F., Woodhouse, A., \& Conner, M. (1998). Beliefs, attitudes and behaviour in relation to supplement use in the UK Women's Cohort Study (UKWCS). Paper presented at the PROCEEDINGS-NUTRITION SOCIETY OF LONDON.

Knight, R. G., Williams, S., McGee, R., \& Olaman, S. (1997). Psychometric properties of the Centre for Epidemiologic Studies Depression Scale (CES-D) in a sample of women in middle life. Behav Res Ther, 35(4), 373-380.

Kooij, D., \& Van De Voorde, K. (2011). How changes in subjective general health predict future time perspective, and development and generativity motives over the lifespan. Journal of Occupational \& Organizational Psychology, 84(2), 228-247. doi:10.1111/j.20448325.2010.02012.x

La Roche, A. N., \& Frankel, A. (1986). Time perspective and health. Health Education Research, 1(2), 139-142. doi:10.1093/her/1.2.139

Lang, F. R., \& Carstensen, L. L. (2002). Time counts: future time perspective, goals, and social relationships. Psychology and aging, 17(1), 125.

Lee, P. N., Foley, B. A., \& Coombs, K. J. (2012). Systematic review with meta-analysis of the epidemiological evidence in the 1900s relating smoking to lung cancer. BMC Cancer, 12(1), 385-474. doi:10.1186/1471-2407-12-385

Levy, D. T., Ellis, J. A., Mays, D., \& An-Tsun, H. (2013). Smoking-related deaths averted due to three years of policy progress. Bulletin of the World Health Organization, 91(7), 509-518 510p. doi:10.2471/BLT.12.113878

Lewinsohn, P. M., Seeley, J. R., Roberts, R. E., \& Allen, N. B. (1997). Center for Epidemiologic Studies Depression Scale (CES-D) as a screening instrument for depression among community-residing older adults. Psychol Aging, 12(2), 277-287. 
Liangpunsakul, S., Haber, P., \& McCaughan, G. (2016). Alcoholic liver disease in Asia, Europe, and North America. Gastroenterology. doi:10.1053/j.gastro.2016.02.043

Lieberman, H. R. (2007). Hydration and cognition: A critical review and recommendations for future research. Journal of the American College of Nutrition, 26(sup5), 555S-561S. doi:10.1080/07315724.2007.10719658

Lim, S. S., Vos, T., Flaxman, A. D., Danaei, G., Shibuya, K., Adair-Rohani, H., . . Memish, Z. A. (2012). A comparative risk assessment of burden of disease and injury attributable to 67 risk factors and risk factor clusters in 21 regions, 1990-2010: A systematic analysis for the Global Burden of Disease Study 2010. The Lancet, 380(9859), 2224-2260. doi:10.1016/S0140-6736(12)61766-8

Linos, E., Keiser, E., Fu, T., Colditz, G., Chen, S., \& Tang, J. Y. (2011). Hat, shade, long sleeves, or sunscreen? Rethinking US sun protection messages based on their relative effectiveness. Cancer Causes \& Control, 22(7), 1067-1071.

Lock, K., Pomerleau, J., Causer, L., Altmann, D. R., \& McKee, M. (2005). The global burden of disease attributable to low consumption of fruit and vegetables: Implications for the global strategy on diet. Bulletin of the World Health Organization, 83(2), 100-108.

Löckenhoff, C. E., \& Carstensen, L. L. (2004). Socioemotional selectivity theory, aging, and health: The increasingly delicate balance between regulating emotions and making tough choices. Journal of personality, 72(6), 1395-1424.

Lopez-Quintero, C., Cobos, J. P., Hasin, D. S., Okuda, M., Wang, S., Grant, B. F., \& Blanco, C. (2011). Probability and predictors of transition from first use to dependence on nicotine, alcohol, cannabis, and cocaine: Results of the National Epidemiologic Survey on Alcohol 
and Related Conditions (NESARC). Drug Alcohol Depend, 115(1), 120-130. doi:10.1016/j.drugalcdep.2010.11.004

Lopez, A. D., Mathers, C. D., Ezzati, M., Jamison, D. T., \& Murray, C. J. (2006). Global and regional burden of disease and risk factors, 2001: Systematic analysis of population health data. The Lancet, 367(9524), 1747-1757. doi:10.1016/S0140-6736(06)68770-9

Lorenzoni, L., Belloni, A., \& Sassi, F. (2014). Health-care expenditure and health policy in the USA versus other high-spending OECD countries. The Lancet, 384(9937), 83-92. doi:10.1016/S0140-6736(14)60571-7

Lukwago, S. N., Kreuter, M. W., Holt, C. L., Steger-May, K., Bucholtz, D. C., \& Skinner, C. S. (2003). Sociocultural correlates of breast cancer knowledge and screening in urban African American women. American Journal of Public Health, 93(8), 1271-1274.

MacLeod, A. K., \& Conway, C. (2007). Well-being and positive future thinking for the self versus others. Cognition and Emotion, 21(5), 1114-1124. doi:10.1080/02699930601109507

MacLeod, A. K., \& Salaminiou, E. (2001). Reduced positive future-thinking in depression: Cognitive and affective factors. Cognition \& Emotion, 15(1), 99-107.

Masoodi, N. A. (2011, 12//). Efficacy and safety of dietary supplement use in the primary prevention of chronic disease in the general non-pregnant United States adult population, Editorial. British Journal of Medical Practitioners, pp. 4-5. Retrieved from http://search.ebscohost.com/login.aspx?direct=true\&db=a9h\&AN=70497832\&site=ehost -live

Matsumoto, C., Miedema, M. D., Ofman, P., Gaziano, J. M., \& Sesso, H. D. (2014). An expanding knowledge of the mechanisms and effects of alcohol consumption on 
cardiovascular disease. Journal of Cardiopulmonary Rehabilitation and Prevention, 34(3), 159-171. doi:10.1097/HCR.0000000000000042

Mello, Z. R., Finan, L. J., \& Worrell, F. C. (2013). Introducing an instrument to assess time orientation and time relation in adolescents. J Adolesc, 36(3), 551-563. doi:10.1016/j.adolescence.2013.03.005

Mello, Z. R., \& Worrell, F. C. (2006). The relationship of time perspective to age, gender, and academic achievement among academically talented adolescents. Journal for the Education of the Gifted, 29(3), 271-289.

Mello, Z. R., \& Worrell, F. C. (2007). The adolescent time inventory-English. Unpublished scale The University of California, Berkeley.

Mello, Z. R., Zhang, J. W., Barber, S. J., Paoloni, V. C., Howell, R. T., \& Worrell, F. C. (2016). Psychometric properties of time attitude scores in young, middle, and older adult samples. Personality and Individual Differences, 101, 57-61. doi:http://dx.doi.org/10.1016/j.paid.2016.05.037

Miech, R. A., Johnston, L. D., O’Malley, P. M., Bachman, J. G., \& Schulenberg, J. E. (2015). Monitoring the Future national survey results on drug use, 1975-2014.

Mirmiran, P., Noori, N., Zavareh, M. B., \& Azizi, F. (2009). Fruit and vegetable consumption and risk factors for cardiovascular disease. Metabolism, 58(4), 460-468. doi:http://dx.doi.org/10.1016/j.metabol.2008.11.002

Moore, L. V., \& Thompson, F. E. (2015). Adults meeting fruit and vegetable intake recommendations-United States, 2013. Morbidity and Mortality Weekly Report, 64(26), 709-713. 
Morgan, M. A. (2015). Analyzing seat belt usage from accident data: An evaluation of Click It or Ticket enforcement campaigns in Ohio. Int'l J. Police Sci. \& Mgmt., 17, 32.

Muraki, I., Imamura, F., Manson, J. E., Hu, F. B., Willett, W. C., van Dam, R. M., \& Sun, Q. (2013). Fruit consumption and risk of type 2 diabetes: Results from three prospective longitudinal cohort studies. $B M J$.

Myung, S., Ju, W., Cho, B., Oh, S., Park, S. M., Koo, B., \& Park, B. (2013). Efficacy of vitamin and antioxidant supplements in prevention of cardiovascular disease: Systematic review and meta-analysis of randomised controlled trials. The BMJ, 346, f10.

doi:10.1136/bmj.f10

Nelson, D. E., Jarman, D. W., Rehm, J., Greenfield, T. K., Rey, G., Kerr, W. C., . . Naimi, T. S. (2013). Alcohol-attributable cancer deaths and years of potential life lost in the United States. American Journal of Public Health, 103(4), 641-648.

doi:10.2105/AJPH.2012.301199

NHSTA. (2000). Occupant protection. National Highway Traffic Safety Administration, DOT HS, 809, 327.

NHTSA. (1984). Amendment to federal motor vehicle safety standard no. 208: Passenger car front seat occupant protection. Federal Regulatory Impact Analysis. Washington, DC: US Dept ofTransportation, National Highway Traffic Safety Administration.

NHTSA. (2015). Occupant protection: 2013 data. Traffic Safety Facts DOT HS 812 153, Washington, DC: National Highway Traffic Safety Administration.

Nichols, J. L., Tippetts, A. S., Fell, J. C., Eichelberger, A. H., \& Haseltine, P. W. (2014). The effects of primary enforcement laws and fine levels on seat belt usage in the United States. Traffic Injury Prevention, 15(6), 640-644. doi:10.1080/15389588.2013.857017 
Oncken, C., McKee, S. A., Krishnan-Sarin, S., O'Malley, S. S., \& Mazure, C. M. (2005). Knowledge and perceived risk of smoking-related conditions: A survey of cigarette smokers. Preventive Medicine, 40(6), 779-784. doi:http://dx.doi.org/10.1016/j.ypmed.2004.09.024

Ortman, J. M., \& Velkoff, V. A. (2014). An aging nation: The older population in the United States. Current Population Reports, 25-1140.

Oza, S., Thun, M. J., Henley, S. J., Lopez, A. D., \& Ezzati, M. (2011). How many deaths are attributable to smoking in the United States? Comparison of methods for estimating smoking-attributable mortality when smoking prevalence changes. Preventive Medicine, 52(6), 428-433. doi:http://dx.doi.org/10.1016/j.ypmed.2011.04.007

Paixão, M. P., da Silva, J. T., Ortuño, V., \& Cordeiro, P. (2013). International studies in time perspective: Imprensa da Universidade de Coimbra/Coimbra University Press.

Palmer, M. E., Haller, C., McKinney, P. E., Klein-Schwartz, W., Tschirgi, A., Smolinske, S. C., . . . Landzberg, B. R. (2003). Adverse events associated with dietary supplements: An observational study. The Lancet, 361(9352), 101-106. doi:http://dx.doi.org/10.1016/S0140-6736(03)12227-1

Paraskevaides, T., Morgan, C. J. A., Leitz, J. R., Bisby, J. A., Rendell, P. G., \& Curran, H. V. (2009). Drinking and future thinking: acute effects of alcohol on prospective memory and future simulation. Psychopharmacology (Berl), 208(2), 301. doi:10.1007/s00213-009$1731-0$

Pelucchi, C., Tramacere, I., Boffetta, P., Negri, E., \& Vecchia, C. L. (2011). Alcohol consumption and cancer risk. Nutrition \& Cancer, 63(7), 983-990 988p. doi:10.1080/01635581.2011.596642 
Petry, N. M., Bickel, W. K., \& Arnett, M. (1998). Shortened time horizons and insensitivity to future consequences in heroin addicts. Addiction, 93(5), 729-738.

Pickrell, T. M. (2014). Seat belt use in 2013-Overall results. Retrieved from

Pierce, J. P., Messer, K., White, M. M., Cowling, D. W., \& Thomas, D. P. (2011). Prevalence of heavy smoking in California and the United States, 1965-2007. JAMA, 305(11), 11061112. doi:10.1001/jama.2011.334

Popkin, B. M., D'Anci, K. E., \& Rosenberg, I. H. (2010). Water, hydration, and health. Nutrition Reviews, 68(8), 439-458.

Preacher, K. J., \& Hayes, A. F. (2004). SPSS and SAS procedures for estimating indirect effects in simple mediation models. Behavior Research Methods, Instruments, \& Computers, 36(4), 717-731.

Radloff, L. S. (1977). The CES-D scale a self-report depression scale for research in the general population. Applied Psychological Measurement, 1(3), 385-401.

Rehm, J., Mathers, C., Popova, S., Thavorncharoensap, M., Teerawattananon, Y., \& Patra, J. (2009). Global burden of disease and injury and economic cost attributable to alcohol use and alcohol-use disorders. The Lancet, 373(9682), 2223-2233. doi:http://dx.doi.org/10.1016/S0140-6736(09)60746-7

Rehm, J., Samokhvalov, A. V., \& Shield, K. D. (2013). Global burden of alcoholic liver diseases. Journal of Hepatology, 59(1), 160-168.

Rehm, J., Taylor, B., Mohapatra, S., Irving, H., Baliunas, D., Patra, J., \& Roerecke, M. (2010). Alcohol as a risk factor for liver cirrhosis: A systematic review and meta-analysis. Drug Alcohol Rev, 29(4), 437-445. 
Reinert, A., Rohrmann, S., Becker, N., \& Linseisen, J. (2007). Lifestyle and diet in people using dietary supplements. European Journal of Nutrition, 46(3), 165-173. doi:10.1007/s00394-007-0650-2

Rogers, H. W., Weinstock, M. A., Harris, A. R., Hinckley, M. R., Feldman, S. R., Fleischer, A. B., \& Coldiron, B. M. (2010). Incidence estimate of nonmelanoma skin cancer in the United States, 2006. Arch Dermatol, 146(3), 283-287. doi:10.1001/archdermatol.2010.19

Room, R., Babor, T., \& Rehm, J. (2005). Alcohol and public health. The Lancet, 365(9458), 519530. doi:http://dx.doi.org/10.1016/S0140-6736(05)17870-2

Salahuddin, S., Prabhakaran, D., \& Roy, A. (2012). Pathophysiological mechanisms of tobaccorelated CVD. Global Heart, 7(2), 113-120. doi:http://dx.doi.org/10.1016/j.gheart.2012.05.003

Sambandan, D. R., \& Ratner, D. (2011). Sunscreens: An overview and update. Journal of the American Academy of Dermatology, 64(4), 748-758. doi:10.1016/j.jaad.2010.01.005

SAMSHA. (2016). Results from the 2015 National Survey on Drug Use and Health: Summary of national findings. from Substance Abuse and Mental Health Services Administration

Savage, C. L. (2014). The role of alcohol in the cancer epidemic. Journal of Addictions Nursing, 25(3), 157-158. doi:10.1097/JAN.0000000000000040

Schoenborn, C. A., Adams, P. F., \& Peregoy, J. A. (2013). Health behaviors of adults: United States, 2008-2010. Vital Health Stat 10(257), 1-184.

Sebastian, R. S., Cleveland, L. E., Goldman, J. D., \& Moshfegh, A. J. (2007). Older adults who use vitamin/mineral supplements differ from nonusers in nutrient intake adequacy and dietary attitudes. Journal of the American Dietetic Association, 107(8), 1322-1332. doi:http://dx.doi.org/10.1016/j.jada.2007.05.010 
Secades-Villa, R., Olfson, M., Okuda, M., Velasquez, N., Perez-Fuentes, G., Liu, S. M., \& Blanco, C. (2013). Trends in the prevalence of tobacco use in the United States, 19911992 to 2004-2005. Psychiatric Services, 64(5), 458-465. doi:10.1176/appi.ps.002852012

Shafer, A. B. (2006). Meta-analysis of the factor structures of four depression questionnaires: Beck, CES-D, Hamilton, and Zung. Journal of Clinical Psychology, 62(1), 123-146. doi:10.1002/jclp.20213

Sharp, R. L. (2007). Role of whole foods in promoting hydration after exercise in humans. Journal of the American College of Nutrition, 26(sup5), 592S-596S.

Siegel, R. L., Jacobs, E. J., Newton, C. C., Feskanich, D., Freedman, N. D., Prentice, R. L., \& Jemal, A. (2015). Deaths due to cigarette smoking for 12 smoking-related cancers in the United States. JAMA Internal Medicine.

Simões, M. C. F., Sousa, J. J. S., \& Pais, A. A. C. C. (2015). Skin cancer and new treatment perspectives: A review. Cancer Letters, 357(1), 8-42. doi:http://dx.doi.org/10.1016/j.canlet.2014.11.001

Smoking, U. P. H. S. A. C. o., \& Health. (1964). Smoking and health.

Stahl, S. T., \& Patrick, J. H. (2012). Adults' future time perspective predicts engagement in physical activity. J Gerontol B Psychol Sci Soc Sci, 67(4), 413-416. doi:10.1093/geronb/gbr118

Szpunar, K. K. (2010). Episodic Future Thought: An Emerging Concept. Perspectives on Psychological Science, 5(2), 142-162. doi:10.1177/1745691610362350

Testino, G., Leone, S., Sumberaz, A., \& Borro, P. (2015). Alcohol and cancer. Alcoholism: Clinical and Experimental Research, 39(11), 2261-2261. doi:10.1111/acer.12858 
Thun , M. J., Carter , B. D., Feskanich , D., Freedman , N. D., Prentice , R., Lopez , A. D., .. . Gapstur , S. M. (2013). 50-year trends in smoking-related mortality in the United States. New England Journal of Medicine, 368(4), 351-364. doi:doi:10.1056/NEJMsa1211127

Timbo, B. B., Ross, M. P., McCarthy, P. V., \& Lin, C. J. (2006). Dietary supplements in a national survey: Prevalence of use and reports of adverse events. Journal of the American Dietetic Association, 106(12), 1966-1974. doi:http://dx.doi.org/10.1016/j.jada.2006.09.002

van der Horst, K., \& Siegrist, M. (2011). Vitamin and mineral supplement users. Do they have healthy or unhealthy dietary behaviours? Appetite, 57(3), 758-764. doi:http://dx.doi.org/10.1016/j.appet.2011.08.020

Van Duyn, M. S., \& Pivonka, E. (2000). Overview of the health benefits of fruit and vegetable consumption for the dietetics professional: Selected literature. Journal of the American Dietetic Association, 100(12), 1511-1521. doi:http://dx.doi.org/10.1016/S0002$\underline{8223(00) 00420-X}$

Visser, P. L., \& Hirsch, J. K. (2014). Health behaviors among college students: The influence of future time perspective and basic psychological need satisfaction. Health Psychol Behav Med, 2(1), 88-99. doi:10.1080/21642850.2013.872992

Ward, E. (2014). Addressing nutritional gaps with multivitamin and mineral supplements. Nutrition Journal, 13, 72-72. doi:10.1186/1475-2891-13-72

Webster, J. D., \& Ma, X. D. (2013). A Balanced Time Perspective in Adulthood: Well-being and Developmental Effects. Canadian Journal On Aging-Revue Canadienne Du Vieillissement, 32(4), 433-442. doi:10.1017/S0714980813000500 
White, I. R., Altmann, D. R., \& Nanchahal, K. (2002). Alcohol consumption and mortality: modelling risks for men and women at different ages. BMJ, 325(7357), 191.

Whiteford, H. A., Degenhardt, L., Rehm, J., Baxter, A. J., Ferrari, A. J., Erskine, H. E., . . . Johns, N. (2013). Global burden of disease attributable to mental and substance use disorders: findings from the Global Burden of Disease Study 2010. The Lancet, 382(9904), 1575-1586.

WHO. (2005). Nutrients in drinking water.

WHO. (2009). Global health risks: mortality and burden of disease attributable to selected major risks: World Health Organization.

WHO. (2013). WHO global status report on road safety 2013: supporting a decade of action: World Health Organization.

WHO. (2014). Global status report on alcohol and health, 2014.

Williams, C. D., Taylor, T. R., Makambi, K., Harrell, J., Palmer, J. R., Rosenberg, L., \& AdamsCampbell, L. L. (2007). CES-D four-factor structure is confirmed, but not invariant, in a large cohort of African American women. Psychiatry Res, 150(2), 173-180. doi:10.1016/j.psychres.2006.02.007

Wong, T., \& Orton, D. (2011). Sunscreen allergy and its investigation. Clinics in Dermatology, 29(3), 306-310. doi:http://dx.doi.org/10.1016/j.clindermatol.2010.11.002

Woolf, S. H. (2008). The power of prevention and what it requires. JAMA, 299(20), 2437-2439.

Worrell, F. C., \& Mello, Z. R. (2009). Convergent and discriminant validity of time attitude scores on the Adolescent Time Perspective Inventory. Diskurs Kindheits-und Jugendforschung, 4(2). 
Worrell, F. C., Mello, Z. R., \& Buhl, M. (2013). Introducing English and German versions of the Adolescent Time Attitude Scale. Assessment, 20(4), 496-510. doi:10.1177/1073191110396202

Wu, Y., Zhang, D., Jiang, X., \& Jiang, W. (2015). Fruit and vegetable consumption and risk of type 2 diabetes mellitus: A dose-response meta-analysis of prospective cohort studies. Nutrition, Metabolism and Cardiovascular Diseases, 25(2), 140-147. doi:http://dx.doi.org/10.1016/j.numecd.2014.10.004

Younossi, Z., \& Henry, L. Contribution of alcoholic and non-alcoholic fatty liver disease to the burden of liver-related morbidity and mortality. Gastroenterology. doi:http://dx.doi.org/10.1053/j.gastro.2016.03.005

Zamoiski, R. D., Cahoon, E. K., Freedman, D. M., \& Linet, M. S. (2015). Self-reported sunscreen use and urinary benzophenone-3 concentrations in the United States: NHANES 2003-2006 and 2009-2012. Environmental Research, 142, 563-567.

Zhan, J., Liu, Y., Cai, L., Xu, F., Xie, T., \& He, Q. (2015). Fruit and vegetable consumption and risk of cardiovascular disease: A meta-analysis of prospective cohort studies. Critical Reviews in Food Science and Nutrition, 00-00. doi:10.1080/10408398.2015.1008980

Zimbardo, P. G., \& Boyd, J. N. (1999). Putting time in perspective: A valid, reliable individualdifferences metric. Journal of Personality and Social Psychology, 77(6), 1271-1288. doi:10.1037/0022-3514.77.6.1271

Zimbardo, P. G., Keough, K. A., \& Boyd, J. N. (1997). Present time perspective as a predictor of risky driving. Personality and Individual Differences, 23(6), 1007-1023. doi:http://dx.doi.org/10.1016/S0191-8869(97)00113-X 


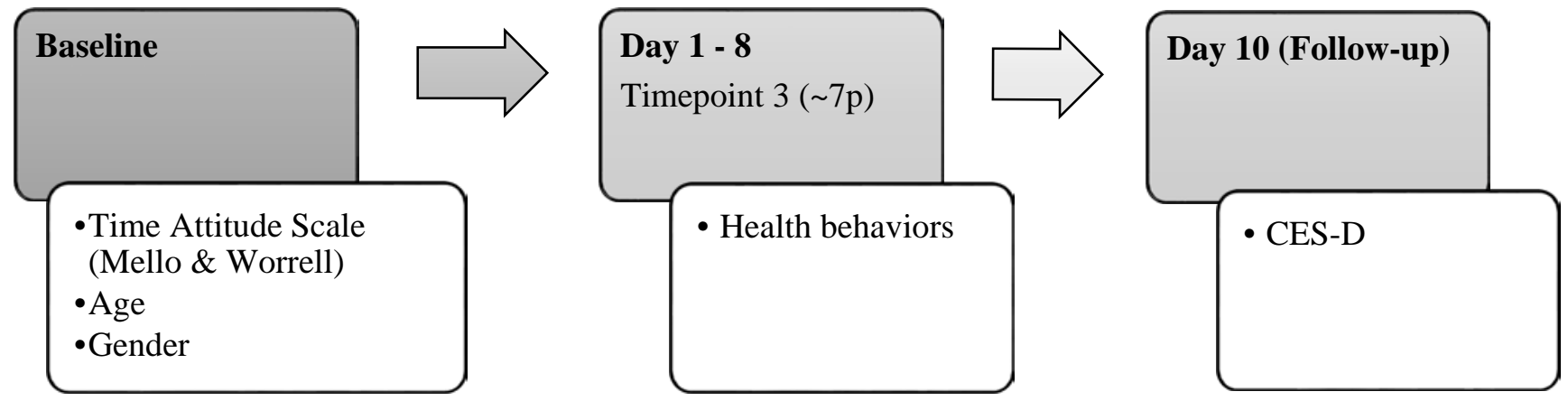

Figure 1. Study design flowchart 


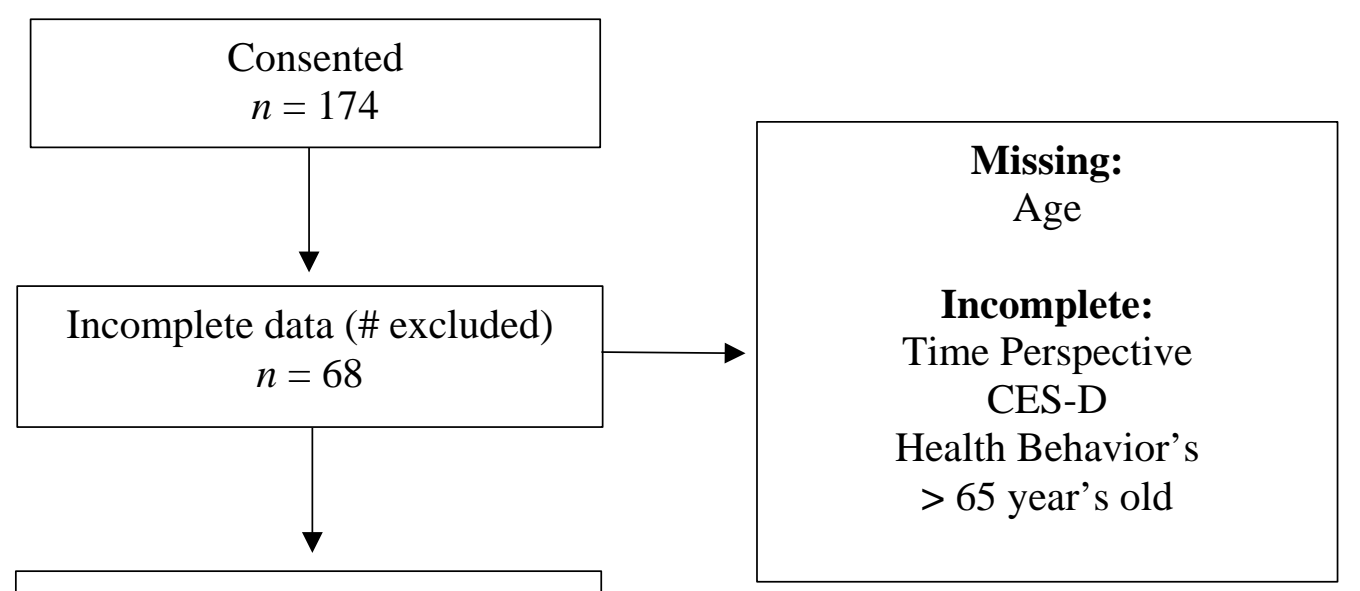

Complete data used for analysis

$$
n=106
$$

Figure 2. Participant retention flowchart 
Table 1

Independent samples t-test comparing individuals with complete data (included in the moderation analysis and those excluded from moderation analysis due to missingness

\begin{tabular}{|c|c|c|c|c|c|c|}
\hline \multirow[b]{2}{*}{ Variable Name (Missing data sample size) } & \multicolumn{2}{|c|}{$\begin{array}{l}\text { Missing Data } \\
\quad(n=68)\end{array}$} & \multicolumn{2}{|c|}{$\begin{array}{l}\text { Complete data } \\
\quad(n=106)\end{array}$} & \multirow[b]{2}{*}{ t-test } & \multirow[b]{2}{*}{ p-value } \\
\hline & Mean & SD & Mean & SD & & \\
\hline Age $(n=54)$ & 43.30 & 18.65 & 35.21 & 12.67 & 2.868 & .005 \\
\hline Gender $(n=55)$ & 1.73 & .45 & 1.75 & .50 & -.225 & .823 \\
\hline Positive Future Time Perspective ( $n=52$ ) & 3.87 & .89 & 3.87 & .85 & -.005 & .996 \\
\hline CES-D Total Score $(n=41)$ & 14.22 & 12.60 & 13.82 & 11.29 & .186 & .853 \\
\hline Positive Health Behaviors ( $n=67$ ) & .35 & .28 & .35 & .25 & .019 & .985 \\
\hline Negative Health Behaviors $(n=67)$ & .14 & .22 & .13 & .18 & .461 & .645 \\
\hline
\end{tabular}

Mean comparison between missing data and complete data show significant differences on age but, not other key variables. Mean age difference might be explained by $>65$ being excluded from current analyses.

N.B. Gender: Male $=1 ;$ Female $=2$ 
Table 2

Principal Component Analysis for Health Behaviors

Structure Matrix

\begin{tabular}{rccc}
\hline & \multicolumn{3}{c}{ Component } \\
\cline { 2 - 4 } & 1 & 2 & 3 \\
\hline Vegetables & .887 & .029 & .031 \\
Fruit & .806 & .142 & .138 \\
Water & .785 & -.190 & .012 \\
Vitamins & .555 & .007 & .252 \\
Seat Belt & .050 & .822 & -.081 \\
Tobacco & -.028 & .789 & .397 \\
Alcohol & -.075 & .302 & .781 \\
Sunscreen & .337 & -.142 & .720 \\
\hline
\end{tabular}

Rotation Method: Promax with Kaiser Normalization.

Exploratory and confirmatory principal component analyses (PCA) were conducted with the full sample of 174 participants using an oblique rotation (promax). An exploratory PCA verified the sampling adequacy with a Kaiser-Meyer-Olkin = .666 (Field, 2013). Extracted factors accounted for $65.15 \%$ of total variance. Component 1, (31.51\% variance accounted for), vegetable, fruit, vitamin, and water consumption. Component 2, (19.64\% variance accounted for), seatbelt and tobacco use. Component 3, (13.99\% variance accounted for), alcohol and sunscreen use, although both of these variables also loaded in Component 2 and 1 respectively. For structure matrix, please see Table 2. Based on the exploratory results and cross-loading of alcohol and sunscreen use, a 2-factor confirmatory PCA was conducted. These factors accounted for 51.16\% of the variance. Component 1 , which accounted for $31.51 \%$ of the variance, consisted of positive health behaviors (i.e. vegetable, fruit, vitamin, water consumption, and sunscreen use).

Component 2 accounted for an additional 19.64\% of the variance and consisted of negative health behaviors (i.e. tobacco, alcohol. and seatbelt use). 
Table 3

Pearson and Spearman Correlations Among Demographic, Time Perspective, Depression, and Health Behavior Variables

\begin{tabular}{|c|c|c|c|c|c|c|}
\hline Variables & 1 & $2^{\mathrm{a}}$ & 3 & 4 & 5 & 6 \\
\hline \multicolumn{7}{|l|}{ 1. Age } \\
\hline 2. Gender ${ }^{\mathrm{a}}$ & $-.200^{*}$ & & & & & \\
\hline 3. Positive Future Time Perspective & $-.449^{* *}$ & $.212^{*}$ & & & & \\
\hline 4. CES-D Total Score & .137 & .018 & $-.539^{* *}$ & & & \\
\hline 5. Negative Health Behaviors & .169 & -.121 & -.183 & .189 & & \\
\hline 6. Positive Health Behaviors & .112. & .053 & .104 & $-.252^{* *}$ & -.178 & \\
\hline \multicolumn{7}{|c|}{$\begin{array}{l}\text { Note. Gender: } 1 \text { = Male, } 2 \text { = Female } \\
\text { a Spearman's correlation reported } \\
\text { CES-D Total Score = Center for Epidemiological Studies Depression Scale, 20-item depressive } \\
\text { symptomatology severity } \\
{ }^{*} p<.05 \\
{ }^{* *} p<.01\end{array}$} \\
\hline
\end{tabular}




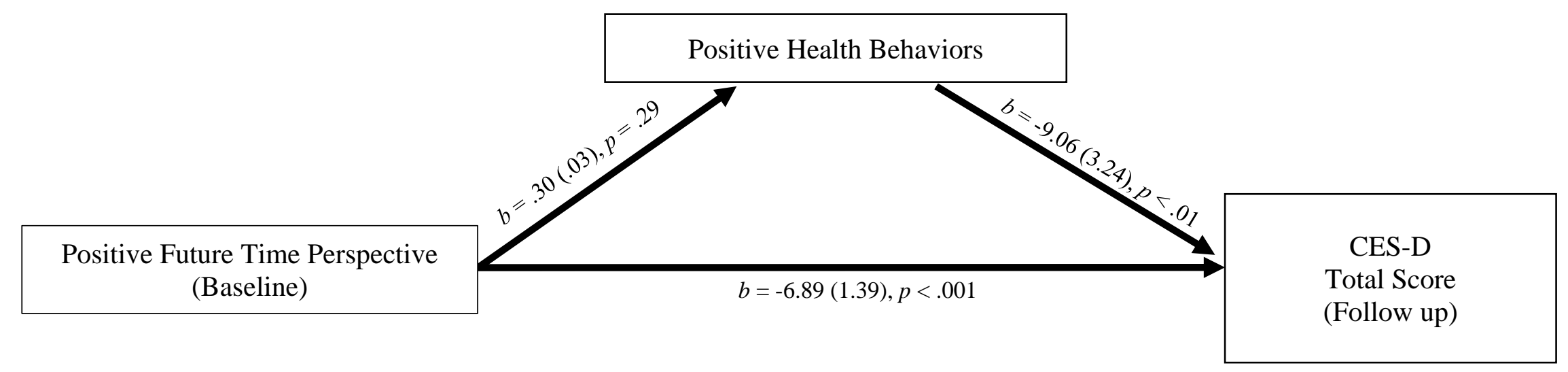

Figure 3. Mediation of the path between positive future time perspective's and depressive symptomatology by positive health behaviors. 


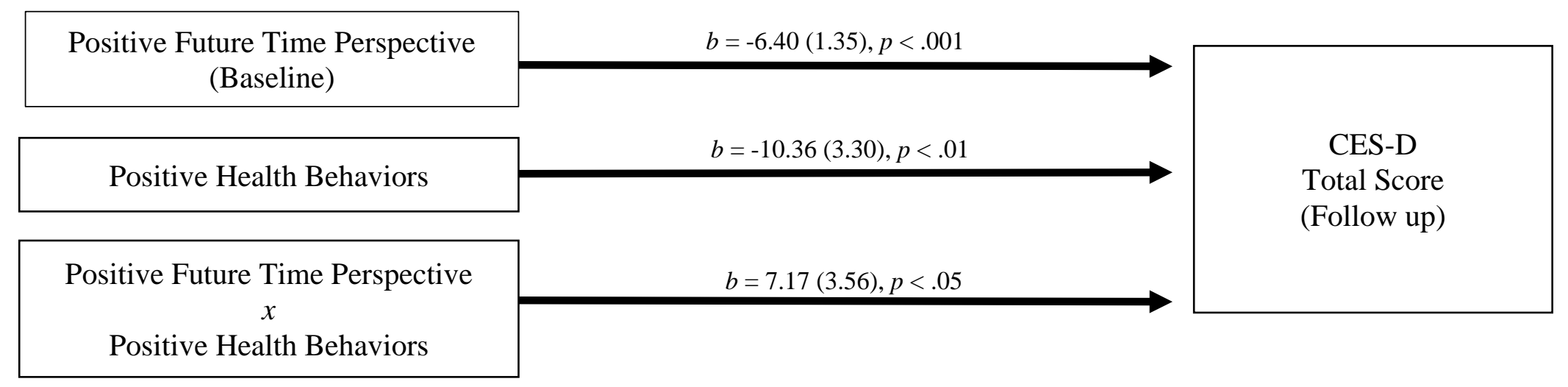

Figure 4. Moderation of the path between positive future time perspective's and depressive symptomatology by positive health behaviors. 


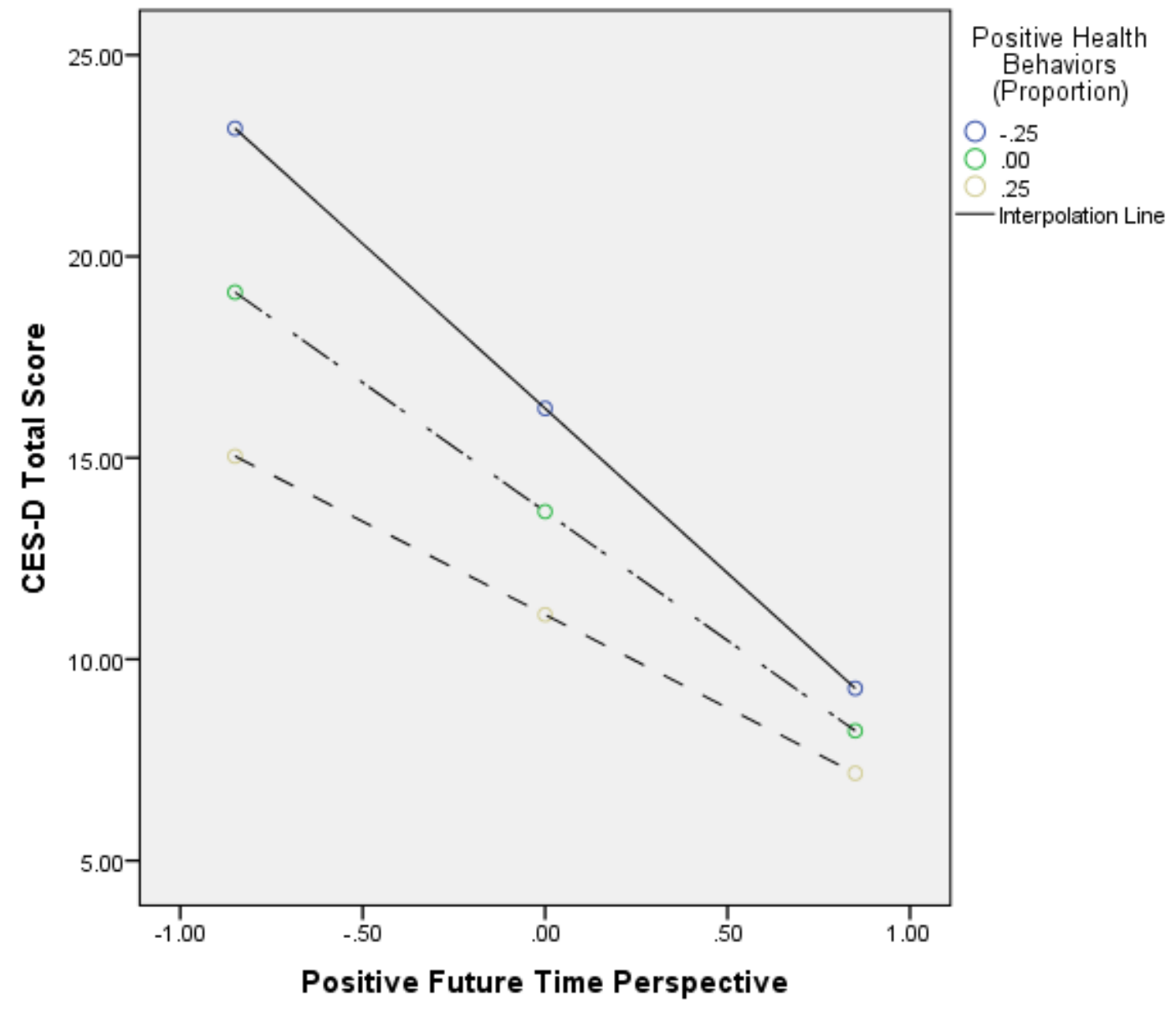

Figure 5. Moderated Regression Interpolation Table. Less positive health behavior engagement was associated with reduced positive future time perspective. As time perspective increased, depressive symptomatology decreased in the low positive health behavior endorsement group. More positive health behavior engagement was associated with lower initial depressive symptomatology and a significant change with increased positive future time perspective. 


\section{Appendix A}

Please indicate your degree of agreement or disagreement with each of the following statements:

I Look forward to my future.

I am not satisfied with my life right now.

I have very happy memories of my childhood.

I doubt I will make something of myself.

I am happy with my current life.

My past is a time in my life that I would like to forget

My future makes me happy.

I have negative feelings about my current situation

I don't think I will amount much in the future.

I am pleased with the present.

I am not satisfied with my past.

My future makes me smile.

I am content with the present.

My past makes me sad.

Thinking about my future makes me sad.

Overall, I feel happy about what I am doing right now

I wish that I did not have the past that I had.

I am excited about my future.

I am not satisfied with my present.

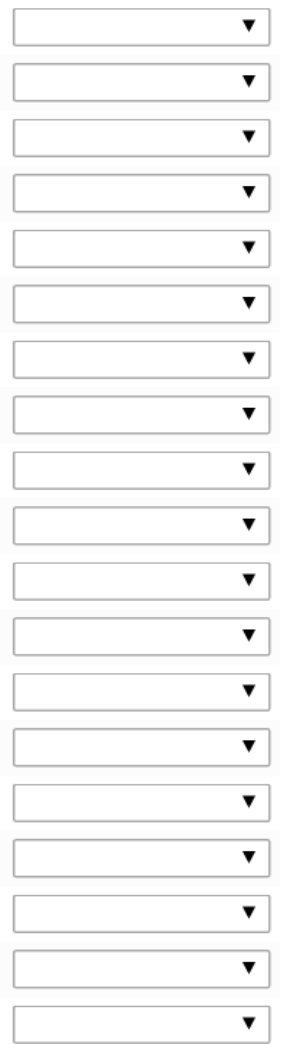

I have happy thoughts about my past.

I don't like to think about my future.

I am not happy with my present life.

I like to think about my past because it was such a happy time for me.

Thinking ahead is pointless.

Overall, I feel happy with my life right now.

I have unpleasant thoughts about my past.

Thinking about my future excites me.

My current life worries me.

My past is full of happy memories.

I have good memories about growing up.

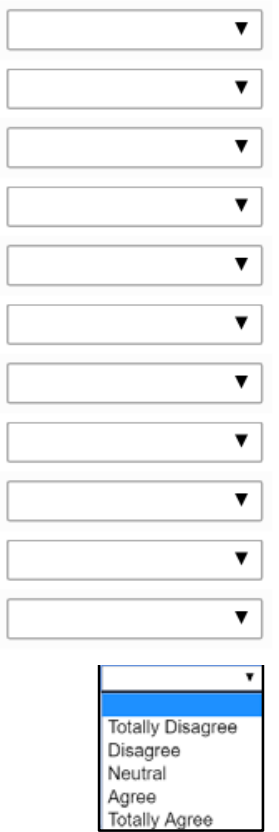

Time Attitude Scale (Mello \& Worrell, 2007) assessed at baseline (day 0). 


\begin{tabular}{|c|c|c|c|}
\hline \multicolumn{4}{|c|}{ Did you engage in these behaviors today? } \\
\hline & No & Yes & Not Applicable \\
\hline Receive something "nice" & ○ & $\bigcirc$ & $\bigcirc$ \\
\hline Used tobacco products & O & ○ & O \\
\hline Drank $8+$ glasses of water & O & $\bigcirc$ & O \\
\hline Ate 1.5 to 2 servings of fruit? & 0 & ○ & ○ \\
\hline $\begin{array}{l}\text { Ate } 2.5 \text { to } 3 \text { servings of } \\
\text { vegetables? }\end{array}$ & $\bigcirc$ & $\bigcirc$ & $\bigcirc$ \\
\hline Wear a seat belt when in a car? & O & ○ & ○ \\
\hline Use sunscreen when outside? & O & ○ & O \\
\hline Take a multi-vitamin? & ○ & $\bigcirc$ & $\bigcirc$ \\
\hline $\begin{array}{l}\text { Drink more than } 1 \text { serving of } \\
\text { alcohol }\end{array}$ & O & ○ & 0 \\
\hline $\begin{array}{l}\text { Do something "nice" for } \\
\text { someone }\end{array}$ & O & O & O \\
\hline Napping & 0 & ○ & ○ \\
\hline
\end{tabular}

Health behaviors response choices assessed at time point 3 ( 7p) for all 8 study days. 
Below are some ways you might have felt during the past week or so. Please indicate how often you have felt each way.

I was bothered by things that usually don't bother me.

I did not feel like eating; my appetite was poor.

I felt that I could not shake off the blues, even with the help of my family or friends

I felt I was just as good as other people.

I had trouble keeping my mind on what I was doing.

I felt depressed.

I felt that everything I did was an effort.

I felt hopeful about the future.

I thought my life had been a failure

I felt fearful.

My sleep was restless.

I was happy.

I talked less than usual.

I felt lonely.

People were unfriendly.

I enjoyed life.

I had crying spells.

I felt sad.

I felt that people disliked me.

I could not get going.

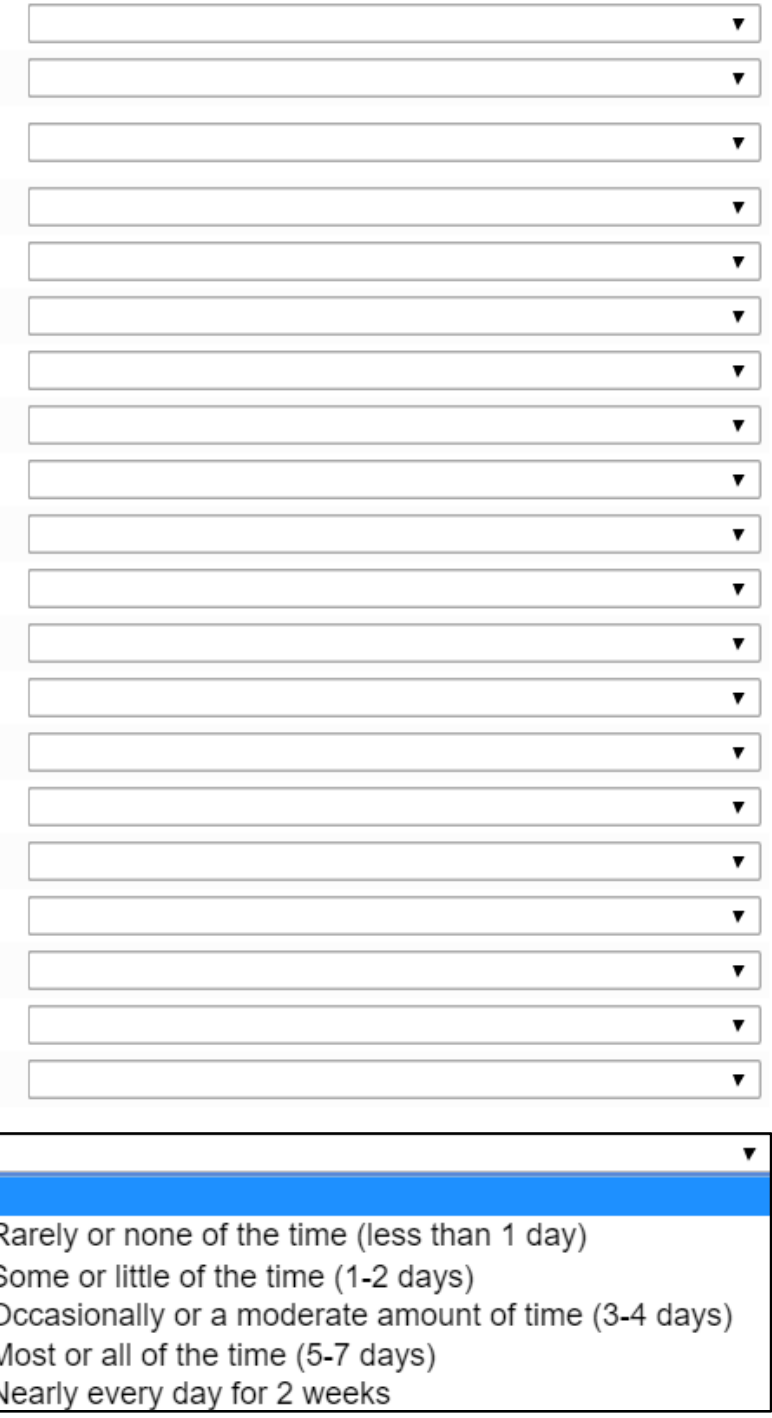

Centre for Epidemiologic Studies Depression Scale (CES-D) assessed at baseline (day 0). 


\section{Appendix B}

\section{Research Question 2:}

How does gender and/or age effect the relations among future time perspective, specific health behaviors and depression?

\section{Hypothesis 2:}

Older individuals with more open future time perspective will endorse more positive health behaviors which will be associated with reduced overall depressive symptoms (Kooij \& Van De Voorde, 2011; Webster \& Ma, 2013). 


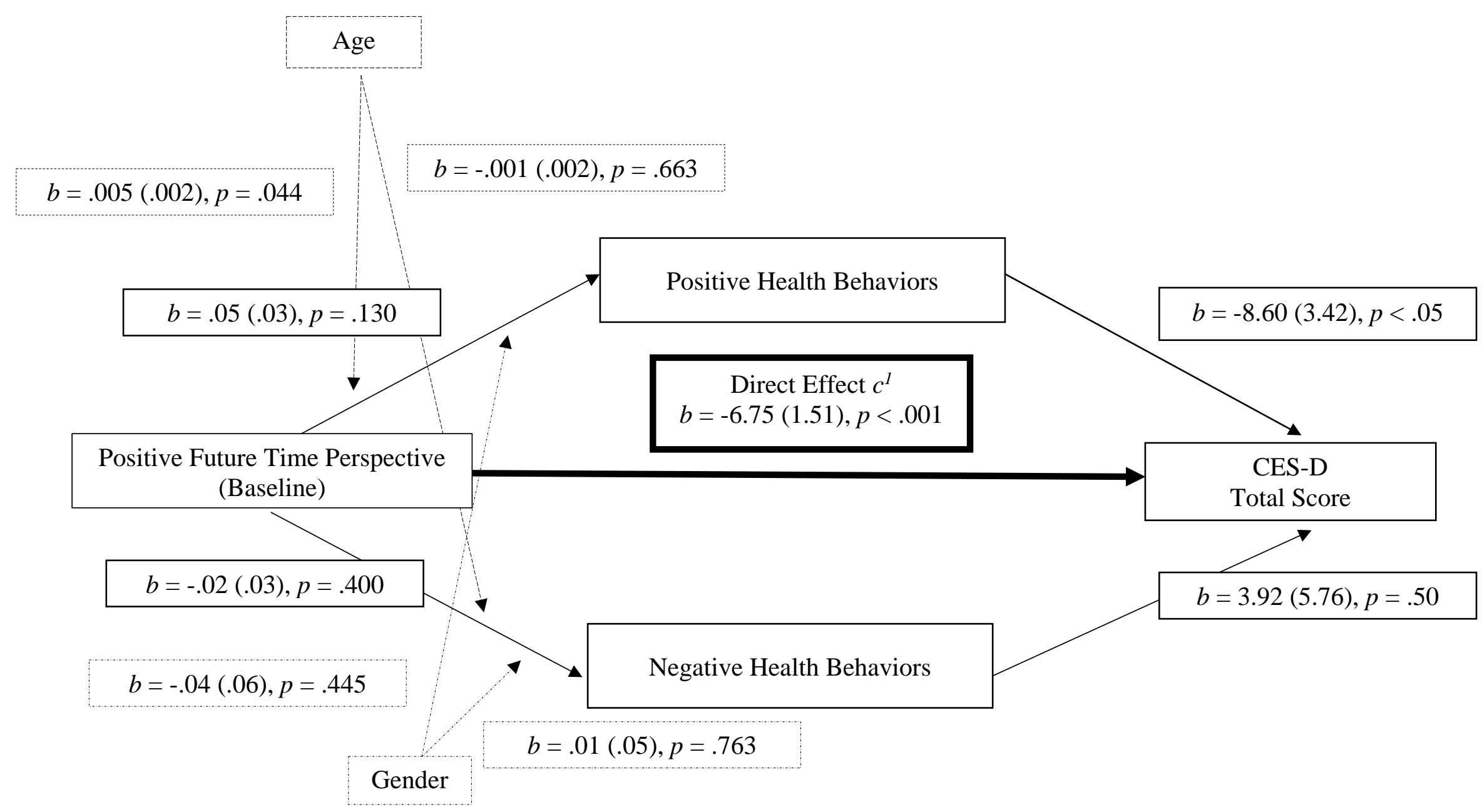

Figure 1. The overall model was significant $F(3,102)=14.14, p<.001, R^{2}=33.3 \%$ whereby future time perspective significantly predicted CES-D total score $(p<.001)$. Positive health behaviors $(p=.014)$ exerted a direct effect, but was not a significant mediator. Negative health behaviors $(p=.498)$ did not exert a direct effect and was not a significant mediator. Additionally, age and gender were not moderators of the positive future time perspective to health behavior association. 


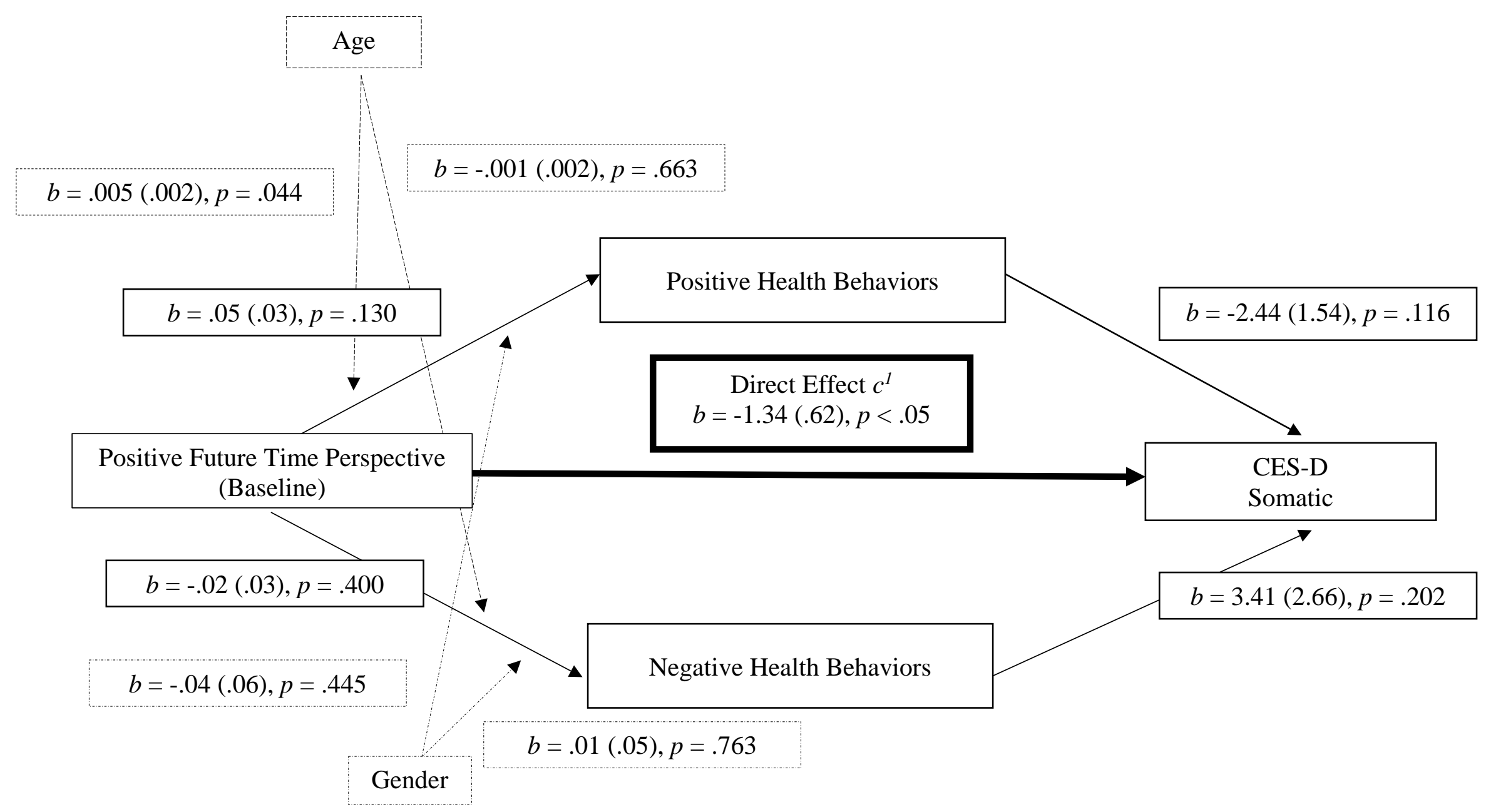

Figure 2. The overall model was significant $F(3,102)=4.37, p<.01, R^{2}=14.1 \%$ whereby future time perspective significantly predicted CES-D Somatic symptoms $(p<.05)$. Both positive health behaviors $(p=.116)$ and negative health behaviors $(p=.202)$ were not significant mediators. Additionally, age and gender were not moderators of the positive future time perspective to health behavior association. 
Table 1

Pearson and Spearman Correlations Among Demographic, Time Perspective, Depression, and Health Behavior Variables.

\begin{tabular}{|c|c|c|c|c|c|c|c|c|c|c|c|c|}
\hline Variables & 1 & $2^{\mathrm{a}}$ & 3 & 4 & $5^{+}$ & $6^{+}$ & $7^{+}$ & $8^{+}$ & $9^{+}$ & $10^{+}$ & 11 & 12 \\
\hline \multicolumn{13}{|l|}{ 1. Age } \\
\hline 2. Gender ${ }^{\mathrm{a}}$ & $-.200^{*}$ & & & & & & & & & & & \\
\hline 3. Race & -.122 & .023 & & & & & & & & & & \\
\hline 4. CES-D Total & .137 & .018 & .135 & & & & & & & & & \\
\hline 5. Past Positive ${ }^{+}$ & $-.338^{* *}$ & -.053 & -.098 & $-.420^{* *}$ & & & & & & & & \\
\hline 6. Past Negative ${ }^{+}$ & $.256^{* *}$ & .029 & .063 & $.507^{* *}$ & $-.741^{* *}$ & & & & & & & \\
\hline 7. Present Positive ${ }^{+}$ & $-.311^{* *}$ & $.217^{*}$ & .004 & $-.643^{* *}$ & $.503^{* *}$ & $-.458^{* *}$ & & & & & & \\
\hline 8. Present Negative ${ }^{+}$ & .186 & -.156 & .003 & $.662^{* *}$ & $-.463^{* *}$ & $.514^{* *}$ & $-.843^{* *}$ & & & & & \\
\hline 9. Future Positive ${ }^{+}$ & $-.449^{* *}$ & $.212^{*}$ & -.143 & $-.539^{* *}$ & $.495^{* *}$ & $-.477^{* *}$ & $.665^{* *}$ & $-.644^{* *}$ & & & & \\
\hline 10. Future Negative ${ }^{+}$ & $.317^{* *}$ & -.100 & .171 & $.602^{* *}$ & $-.523^{* *}$ & $.588^{* *}$ & $-.613^{* *}$ & $.648^{* *}$ & $-.814^{* *}$ & & & \\
\hline 11. Positive Health Behaviors & .112 & .053 & -.030 & $-.252^{* *}$ & -.046 & -.045 & .151 & -.156 & .104 & -.152 & & \\
\hline 12. Negative Health Behaviors & .169 & -.121 & .109 & .189 & $-.252^{* *}$ & .123 & $-.219^{*}$ & .117 & -.183 & .133 & -.178 & \\
\hline \multicolumn{13}{|c|}{$\begin{array}{l}\text { Note. Gender: } 1 \text { = Male, } 2 \text { = Female } \\
\text { a Spearman's correlation reported } \\
{ }^{+} \text {Adolescent Time Inventory - Time Perspective } \\
\text { CES-D Total Score = Center for Epidemiological Studies Depression Scale, 20-item depressive symptomatology severity } \\
{ }^{*} p<.05 \\
{ }^{* *} p<.01\end{array}$} \\
\hline
\end{tabular}




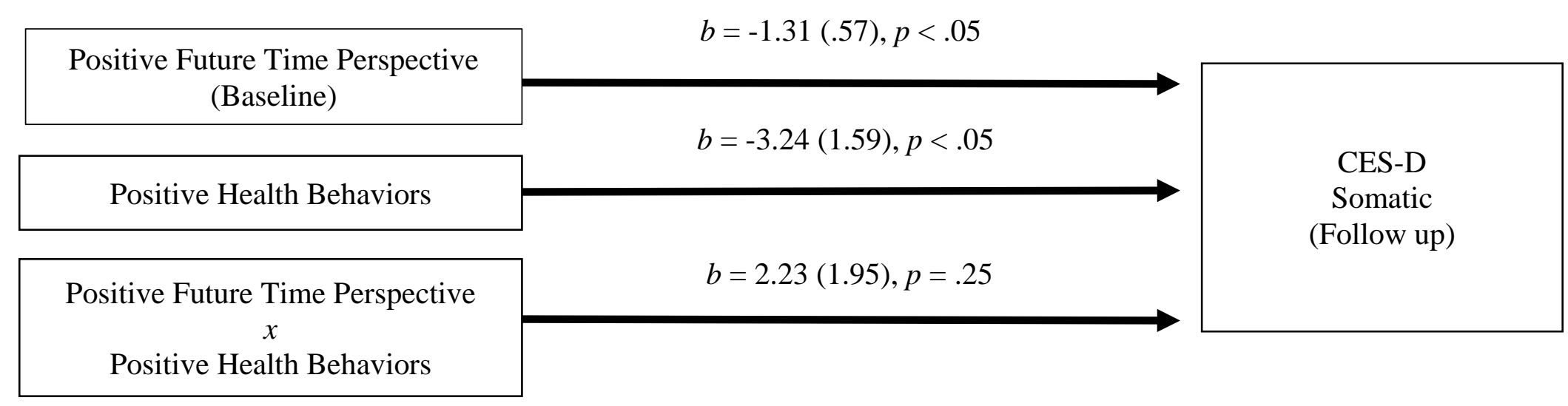

Figure 3. Positive health behavior endorsement moderating the effect of positive future time perspective on somatic depressive symptomatology. 


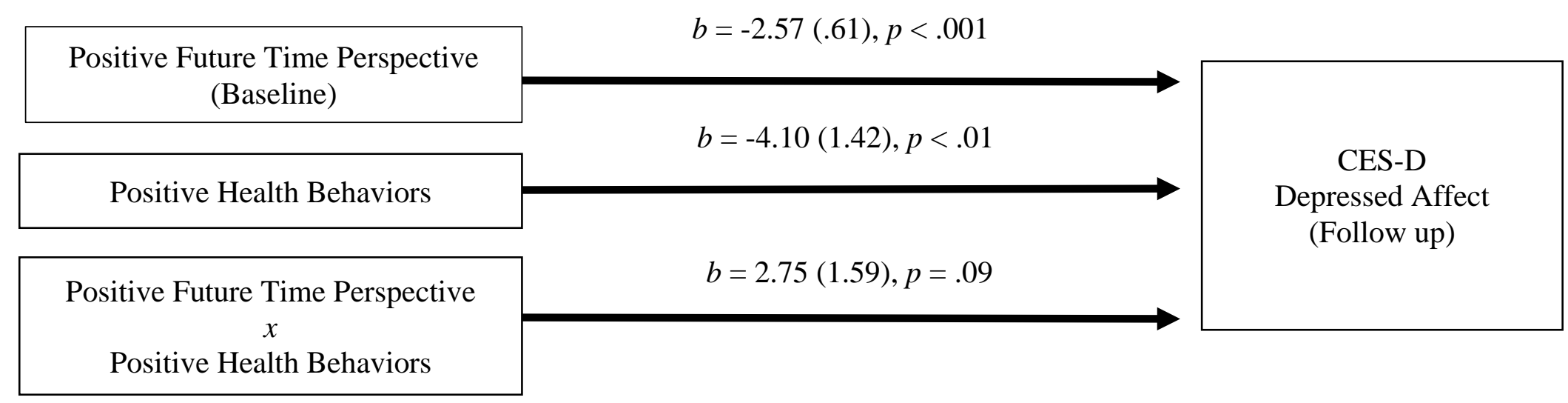

Figure 4. Positive health behavior endorsement moderating the effect of positive future time perspective on depressed affect depressive symptomatology. 


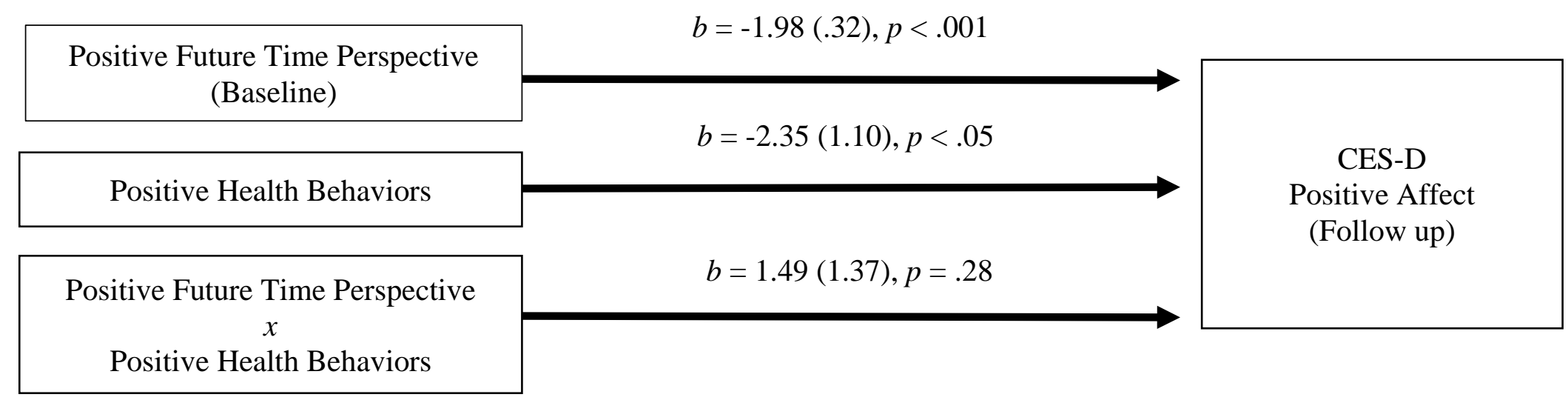

Figure 5. Positive health behavior endorsement moderating the effect of positive future time perspective on positive affect depressive symptomatology. 


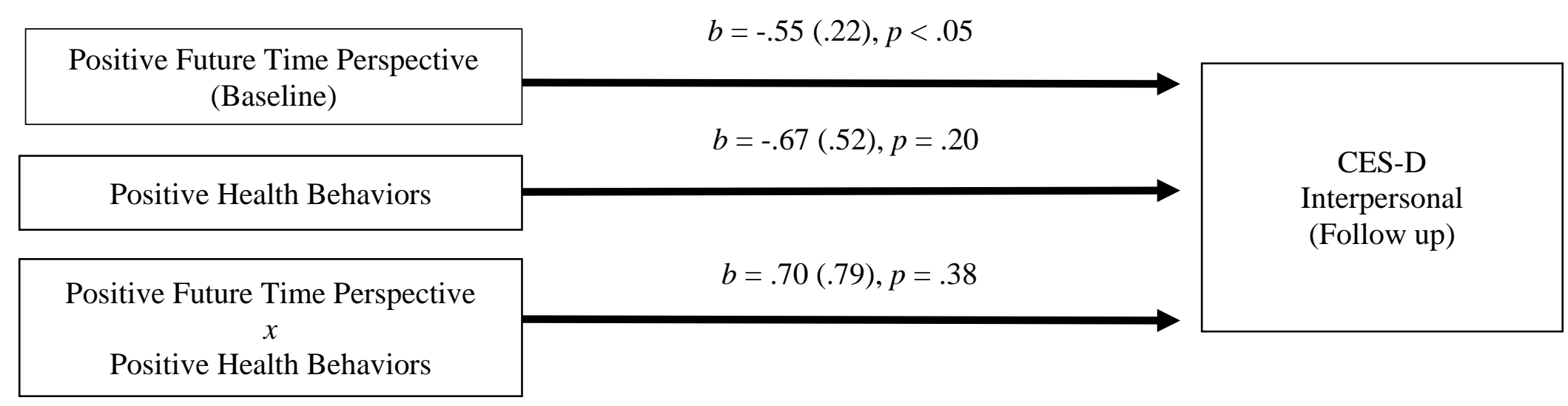

Figure 6. Positive health behavior endorsement moderating the effect of positive future time perspective on interpersonal depressive symptomatology. 


\begin{tabular}{|c|c|c|c|c|c|c|c|c|}
\hline \multirow[b]{3}{*}{ Indirect Effects } & \multicolumn{4}{|c|}{ CES-D Total } & \multicolumn{4}{|c|}{ CES-D Somatic } \\
\hline & $b$ & $\mathrm{SE}$ & $\mathrm{F}$ & $\mathrm{R}^{2}$ & $b$ & SE & $\mathrm{F}$ & $\mathrm{R}^{2}$ \\
\hline & & & & & & & & \\
\hline Positive Health Behaviors & & & 2.17 & .079 & & & 2.17 & .079 \\
\hline Positive Future Time Perspective & .046 & .030 & & & .046 & .030 & & \\
\hline Age $^{++}$ & $.005^{* *}$ & .002 & & & $.005^{* *}$ & .002 & & \\
\hline Gender $^{++}$ & -.043 & .056 & & & -.043 & .056 & & \\
\hline Negative Health Behaviors & & & 1.14 & .065 & & & 1.14 & .065 \\
\hline Positive Future Time Perspective & -.022 & .026 & & & -.022 & .026 & & \\
\hline Age $^{++}$ & -.001 & .002 & & & -.001 & .002 & & \\
\hline Gender $^{++}$ & .014 & .048 & & & .014 & .048 & & \\
\hline Direct Effects & & & & & & & & \\
\hline Positive Health Behaviors & $-8.597^{* *}$ & 3.420 & & & -2.435 & 1.536 & & \\
\hline Negative Health Behaviors & 3.916 & 5.755 & & & 3.409 & 2.656 & & \\
\hline Positive Future Time Perspective & $-6.753^{* *}$ & 1.507 & & & $-1.343^{* *}$ & .617 & & \\
\hline Overall Model $\left(c^{1}\right)$ & & & $14.14^{* *}$ & .333 & & & $4.37^{* *}$ & .141 \\
\hline
\end{tabular}

Figure 1. The overall model for CES-D total was significant $F(3,102)=14.14, p<.001, R^{2}=33.3 \%$ whereby future time perspective significantly predicted CES-D total score $(p<.001)$. Positive health behaviors $(p=.014)$ exerted a direct effect, but was not a significant mediator. Negative health behaviors $(p=.498)$ did not exert a direct effect and was not a significant mediator. Additionally, age and gender were not moderators of the positive future time perspective to health behavior association.

The overall model for CES-D somatic symptoms was significant $F(3,102)=4.37, p<.01, R^{2}=14.1 \%$ whereby future time perspective significantly predicted CES-D somatic symptoms $(p<.05)$. Both positive health behaviors $(p=.116)$ and negative health behaviors $(p=.202)$ were not significant mediators. Additionally, age and gender were not moderators of the positive future time perspective to health behavior association. 